\title{
Cultural dynamics:
}

\section{What is it, what do we know, and what is yet to be known?}

\author{
Yoshihisa Kashima \\ Melbourne School of Psychological Sciences, The University of Melbourne
}

Paul Bain

Department of Psychology, University of Bath

Amy Perfors

Melbourne School of Psychological Sciences, The University of Melbourne

Abstract: 124 words

Text: 10,104 words

Submitted: Annual Review of Psychology

Contact:

Yoshihisa Kashima

Melbourne School of Psychological Sciences

The University of Melbourne

Parkville, Victoria 3010

Australia

Email: ykashima@unimelb.edu.au

Key words: Cultural evolution, cultural change, cultural transmission, social influence, individualism, collectivism 


\begin{abstract}
The psychology of cultural dynamics is the psychological investigation of the formation, maintenance, and transformation of culture over time. This chapter maps out the terrain, reviews the existing literature, and points to the future directions of this research. It is divided into three parts. The first focuses on micro-cultural dynamics, which examines the social and psychological processes that contribute to the dissemination and retention of cultural information. The second, micro-macro dynamics, investigates how micro-level processes give rise to macro-cultural dynamics, which studies how the distribution and long-term trends involving cultural information in a population, and in turn enable and constrain the micro-level processes. We conclude the chapter with a consideration of future directions, pointing to behaviour change research as translational research of cultural dynamics.
\end{abstract}


Despite its chequered history, culture is squarely on the agenda of psychological science. The conception of the person that regards humans as meaning-making and meaningconsuming beings is now well embedded in psychology; culture as a source of meaning is now integral to psychological theorizing (Kashima, 2016a). In the recent past, much of the research on culture-mind interface took a synchronic perspective, generally documenting contemporary cultural differences by comparing human populations around the globe or priming cultural ideas and practices (for a recent review, see Oyserman, 2017). More recently, however, a diachronic perspective called cultural dynamics has emerged (Kashima, 2014, 2016b), which examines how psychological processes are involved in the stability and change of culture over time. In the changing global landscape of the early $21^{\text {st }}$ century $\mathrm{CE}$, a psychological science of cultural dynamics is a necessary complement to the synchronic perspective in culture and psychology.

\section{What is culture and what are its dynamics?}

We conceptualize culture here as the set of socially transmittable information in a population, which can influence cognition, affect, and behaviour (e.g., Kashima, 2016a). This includes ideas and practices, and can be represented in the brain and body, as well as in the

artefacts produced by people (e.g., technologies, mass media, books, websites). Foundational to this perspective is population thinking, i.e., considering cultural information available to a human population as a whole, where a population may be geographically localized, distributed over a wide spatial area or the internet, or even the totality of humanity. This perspective is largely in line with a conception of culture in psychology (e.g., Hong, Morris, Chiu, \& Benet-Martínez, 2000), anthropology and cognitive science (e.g., Boyd \& Richerson, 1985; Sperber, 1996), and biology (e.g., Cavalli-Sforza \& Feldman, 1981; Dawkins, 1976). Cultural dynamics is about the formation, maintenance, and transformation of culture over 
time in this sense. Although this type of approach is often called cultural evolution, we prefer to call it cultural dynamics to clearly demarcate it from social evolutionary theories of the late $19^{\text {th }}$ and early $20^{\text {th }}$ century.

Processes of Cultural Dynamics. There are three main processes in cultural dynamics: how novel cultural information is introduced to a population, how it is transmitted, and how its prevalence changes.

Introducing novel cultural information. How does cultural information become available to a human population? One pathway is invention - novel cultural information, which has not existed in the population, is endogenously produced within the population (for a broad review, see Muthukrishna \& Henrich, 2016). Simonton (2010) suggests that inventive psychological processes often result from combining existing cultural ideas and practices. Innovations appear to show this pattern in online music catalogues and Wikipedia (Tria, Loreto, Servedio, \& Strogatz, 2014), and US patents (Youn, Strumsky, Bettencourt, \& Lobo, 2015). Another pathway is importation, which occurs when cultural information invented elsewhere is brought into a population. There is a growing literature on reactions to imported cultural artefacts (see Morris, Chiu, \& Liu, 2015, for a recent review).

Social transmission of cultural information. Cultural information, once introduced, may be socially transmitted to other individuals. Cavalli-Sforza and Feldman (1981) distinguished three types of cultural transmission: vertical (from parents to their offspring), oblique (from one generation to the next without a genetic relationship), and horizontal (within the same generation). In addition, a reverse-vertical or oblique transmission is possible where cultural transmission occurs from a younger to an older generation; this kind of transmission occurs especially often in new technology domains. We discuss this in greater detail later. 
Altering the prevalence of cultural information. As cultural information is transmitted throughout a population and to next generations, its prevalence (i.e., proportion of people who use it at a given point in time) changes. Cultural drift describes prevalence changes due to random fluctuations. Bentley, Hahn, and Shennan (2004) provided some evidence of cultural drift in baby names in the $20^{\text {th }}$ century US census, pottery motifs from Neolithic Germany, and patents and their citations from the US. However, Acerbi and Bentley (2014) more recently found some departure from purely random cultural drift with color terms, US baby names, and music preferences, as did Sindi and Dale (2016) with a large corpus of word frequency data in Google Ngram (Michel et al., 2011).

The distribution of cultural information may also change due to selection. If cultural information confers some benefits in adapting to the environment, its use is likely reinforced and the likelihood of its future reuse increases. In contrast, if it incurs some costs, the likelihood of its future use is reduced. The net adaptiveness is often called fitness. Fitness enhancing information is likely to increase its prevalence. Although fitness in biological evolution is measured in terms of reproductive success, cultural fitness captures a far broader set of costs and benefits.

Kashima (2018) considered cultural adaptation to a variety of environments. Within a niche constructionist perspective (e.g., Laland, Odling-Smee, \& Feldman, 2000; Oishi, 2014), a human population constructs the human made environment using cultural information available to them (i.e., cultural niche construction) in adaptation to the natural environment; however, the human made environment itself - including the built, social, and psychological environments - presents environmental challenges to the human population. Table 1 summarizes these challenges and lists examples. Cultural information that increases adaptiveness to these environments is selected in and those that decrease adaptiveness are selected out - in this sense, the selection process is said to be Darwinian (Mesoudi, 2011). 
Thus, fitness in a cultural context can include how well the cultural information is adapted to the psychology of the individuals involved, constraints on efficient communication, and the physical and social environment; this complex interaction appears to play an important role in the evolution of words and concepts in colour, kinship, spatial, and numerical domains (Kemp, Xu, \& Regier, 2018).

Table 1: A Variety of Environmental Challenges

\begin{tabular}{|c|c|c|c|}
\hline \multicolumn{3}{|c|}{ Types of Environment } & Examples \\
\hline \multicolumn{3}{|l|}{ Natural } & Climate (e.g., Van de Vliert, 2013) \\
\hline \multirow[t]{5}{*}{ Human Made } & Built & & $\begin{array}{l}\text { Carpentered world (Segall, Campbell, \& } \\
\text { Herskovits, 1966) }\end{array}$ \\
\hline & \multirow[t]{3}{*}{ Social } & Economic & $\begin{array}{l}\text { Mode of production (e.g., Talhelm et al., } \\
\text { 2014; Uskul, Kitayama, \& Nisbett, 2008) }\end{array}$ \\
\hline & & Intergroup & $\begin{array}{l}\text { Competition (e.g., Richerson et al., 2016) } \\
\text { War (e.g., Turchin, Currie, Turner, \& } \\
\text { Gavrilets, 2013) }\end{array}$ \\
\hline & & Intragroup & $\begin{array}{l}\text { Population density (e.g., Gelfand et al., } \\
\text { 2011) } \\
\text { Residential mobility (e.g., Oishi \& Talhelm, } \\
\text { 2012) } \\
\text { Free riders (e.g., Nowak, 2006) }\end{array}$ \\
\hline & \multicolumn{2}{|l|}{ Psychological } & $\begin{array}{l}\text { Anxiety (e.g., Pyszczynski, Solomon, \& } \\
\text { Greenberg, 2015) } \\
\text { Cognitive and communicative capacities } \\
\text { (e.g., Kemp, Xu, \& Regier, 2018) }\end{array}$ \\
\hline
\end{tabular}

While acknowledging that culture helps adaptation and selectionist mechanisms are at play, Sperber and his colleagues (e.g., Claidiere, Scott-Phillips, \& Sperber, 2014) have suggested that culture changes by attraction as well; transmitted cultural information undergoes transformation and eventually ends up in a cultural attractor. Bloodletting as a treatment for illness may be an example (Miton, Claidière, \& Mercier, 2015) - the idea that a physical ailment can be cured by letting blood out from the same location (e.g., bloodletting from head to cure headache) appears to be widespread in diverse traditional cultures and a story about bloodletting is more likely communicated than other equally questionable 
treatments. Although its precise formulation is still to be worked out, this perspective aspires to present an alternative metatheoretical perspective to the neo-Darwinian theory of cultural evolution. Nonetheless, attraction processes may still be understood as adaptation to the psychological environment.

\section{Levels of Analysis in Cultural Dynamics}

Cultural dynamics have been examined at two levels: cultural changes over time at the macro-level and cultural transmission processes at the micro-level. Macro-level cultural trajectories are often perceived by individuals in their social environment and represented as norms (Kashima, Wilson, Lusher, Pearson, \& Pearson, 2013) that impact on micro-level cultural transmission (Kusumi, Hirayama, \& Kashima, 2017). However, the converse also holds: the micro-level activities of individuals interacting in social networks aggregate to affect macro-level cultural dynamics. We review the literatures that attempt to examine this process of emergence.

\section{Micro-level Cultural Dynamics}

Central to micro-level cultural dynamics is the idea that cultural information is socially transmitted: a person who possesses cultural information acts as its sender, and it is taken up by receivers, all in some context. Kashima (2016b) distinguished four subprocesses - production, grounding, interpretation, and memory. In production, cultural information is put into a form that can be interpreted by receivers. Through grounding, the sender and receivers establish a mutual understanding of the cultural information and add it to their common ground. During interpretation, the information is translated to representations in the brain and body of the receiver and stored in memory (Figure 1). 


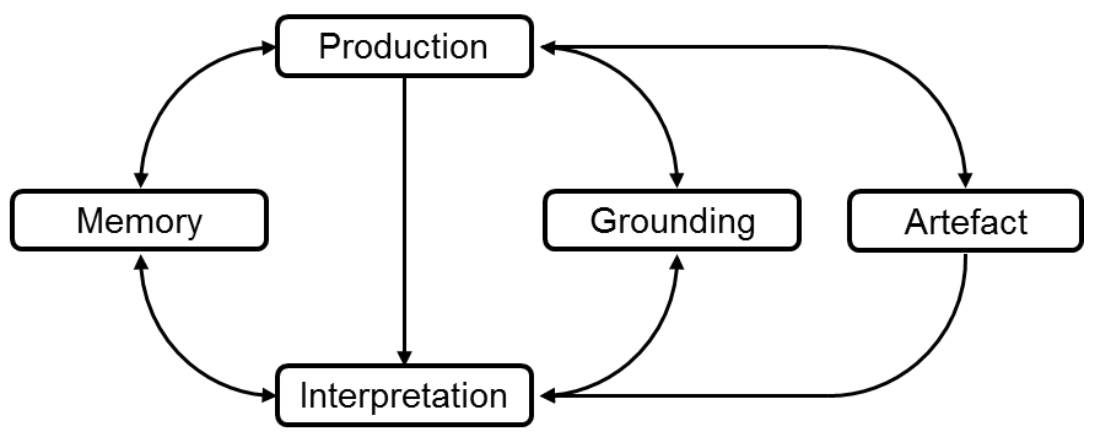

Intrapersonal/Subjective

Interpersonal/Intersubjective

Figure 1: Subprocesses of social transmission of cultural information (Based on Kashima, 2016a).

The processes differ in the extent of subjectivity (memory) and intersubjectivity (grounding), with production and interpretation at their interface. They are conceptually interdependent, and do not have to occur in sequence. For example, cultural transmission can go straight from production to interpretation without grounding, e.g., in instruction, where a sender provides information largely without receivers' acceptance, or in imitation, where a receiver can learn information from a sender, through observation, without the sender's intent to give the information (for a recent review on instruction and imitation, see Legare, 2017). When both the sender and receiver collaboratively exchange information, however, mutual grounding is essential. Cultural artefacts such as songs, books, and other products including TV entertainment and the like on mass media (Morling \& Lamoreaux, 2008; Weisbuch \& Ambady, 2009) are intersubjectively available to the extent that they can be interpreted by those who share a culture. Every time people meaningfully engage with a cultural artefact, it is interpreted and its meaning and memory traces are strengthened for future use. Cultural artefacts can, thus, represent cultural information, and contribute to cultural dynamics regardless of the producers' intent.

Production. Production is constrained by the accessibility of cultural information in the sender's memory as well as the comprehensibility and acceptability of the cultural 
information to the receiver. Given the interdependence among the subprocesses, the method of serial reproduction (Bartlett, 1932) is often used to examine production in cultural transmission. In this method, cultural information is transmitted from one generation of participants to the next generation, who then transmits it to the subsequent generation, and so forth, in a chain. Thus, all subprocesses of cultural transmission are included in the task structure. Typically, each generation consists of one individual, but may include multiple individuals. The use of this method is extensive, spanning animal and human cultural transmission literatures (for recent reviews, see Whiten, Caldwell, \& Mesoudi, 2016).

Grounding. Grounding establishes a mutual understanding called common ground (H. H. Clark, 1996; Kashima, Klein, \& Clark, 2007) about the produced cultural information between the sender and receiver. It typically takes the sender's presentation and the receiver's acceptance of the information; the sender and receiver, then, believe, or take for granted, that they both accept the information for the current purpose. Mutuality is achieved by sending verbal or nonverbal acknowledgment to each other when both people assume or establish they share the same common ground. When cultural information is grounded and mutually shared, the information may take on the status of "shared reality" (Echterhoff, Higgins, \& Levine, 2009) and powerfully engage human psychological processes, inducing stronger emotions (Boothby, Clark, \& Bargh, 2014; Peters \& Kashima, 2007) and motivations (Carr \& Walton, 2014; Shteynberg \& Galinsky, 2011), both of which help to consolidate the memory of the information (Echterhoff, Higgins, Kopietz, \& Groll, 2008).

Interpretation. Although cultural information is often seen to be simply "copied" in cultural transmission, it often involves the receiver's active interpretation (e.g., Bartlett, 1932). Consider the situation where hunter gatherers are foraging for fruits. An experienced forager performs a culturally meaningful action by collecting some fruits and discarding others. Cultural learners can learn to perform the same action by imitation, but may go further 
and interpret that the collected fruits are "good" in some sense. Kashima, Laham, and colleagues' (2015) research suggests that they acquire the meaning of action by active interpretation. In a simulated foraging task, a cultural learner was placed side by side with a cultural old-timer who was knowledgeable about their foraging context. On the shared computer screen, a novel stimulus that represented a fruit was presented, and the old-timer either collected or discarded the fruit using a joystick. The learner learned to perform the same actions by imitation, but also acquired implicit attitudes towards the stimuli - feeling more positively towards the collected than the discarded fruits - in alignment with the oldtimer's actions.

Similarly, Weisbuch, Ambady, and their colleagues (Weisbuch, Pauker, \& Ambady, 2009) found that others' nonverbal behaviours directed towards a group member (e.g., African Americans) in TV shows can transmit cultural information about attitudes towards the target group. In many American TV shows, more negative nonverbal behaviours are directed to African American characters than to White Americans, and viewers of more race biased TV shows tend to have more negative implicit attitudes to African Americans. Furthermore, when participants were exposed to silent video clips of race biased TV programs, they later showed more negative implicit attitudes towards Blacks. Analogously, Weisbuch and Ambady (2009) found an effect of exposure to nonverbal behaviours on women's ideal body size, but they also found this was mediated by perceived cultural ideal body size, suggesting the importance of perceived norms of the cultural group.

Memory. The very act of cultural transmission can itself affect memory. When senders converse with receivers about an event, some aspects are selected and explicitly discussed, whereas other aspects are left out. Hirst, Coman, and their colleagues (Coman \& Hirst, 2012; Coman, Manier, \& Hirst, 2009; Coman, Momennejad, Drach, \& Geana, 2016; Cuc, Ozuru, Manier, \& Hirst, 2006) have shown that what is said in cultural transmission is 
cognitively rehearsed and more likely remembered, but what is left out is more likely forgotten through retrieval induced forgetting (Anderson \& Bell, 2001). When people learn pairs of items that belong to two different categories (e.g., animal-cat, animal-dog, vegetablebroccoli, vegetable-pea), but are induced to retrieve only one pair (e.g., animal-dog), then they tend to forget the other pair in the same category (i.e., animal-cat) even more often than those that were not induced (i.e., vegetable pairs).

Analogous processes occur in the context of cultural transmission in socially shared retrieval-induced forgetting (Cuc et al., 2006). For instance, in Coman et al. (2009), residents of the New York City area were recruited first to ascertain their memories of the September 11 attacks. Their memories were classified into categories such as TIME (e.g., I heard about them at 9am, I woke up at 8am that day) and LOCATION (e.g., I heard about them at home). Two participants were randomly paired to converse about their experiences about the S11 attacks. The conversations were coded for the memories mentioned in the conversation for each participant. Participants who listened to their partner mention his or her memory in a category (TIME - woke up at 7:30am) would have been induced to covertly retrieve their own memory of that type (e.g., I woke up at 8am), but induced to forget their related, but unmentioned memory of that type (e.g., found out about the attacks at 9am) even more than unrelated and unmentioned memory (e.g., heard about them at home). Consistent with this reasoning, a recognition test showed participants responded to the related-but-unretrieved items more slowly and with more errors than either the retrieved items or the unrelated ones. Thus, the act of cultural transmission can select for the transmitted information, but may also inadvertently select out others.

Factors that Influence Cultural Transmission. People tend to transmit information that is instrumental for adaptation to and survival in their environmental niche, as well as 
socially adaptive to their social environment. Nonetheless, context of transmission profoundly affects which information is likely to be transmitted. We address these in turn.

Agency and sociality. Humans appear to be particularly attuned to information about agency. For instance, people tend to recall words for animate beings (e.g., baby, bee, engineer) better than inanimate objects (e.g., doll, drum, journal) even after controlling for word frequency and other factors known to influence recall (Nairne, VanArsdall, Pandeirada, Cogdill, \& LeBreton, 2013). Nairne and Pandeirada (2008) argued that the human memory system evolved in adaptation to the hunter-gatherer environment, and so people tend to recall information better when it is encoded in terms of its relevance for survival in a huntergatherer setting such as foraging than when encoded for its relevance for scavenging (Nairne, Pandeirada, Gregory, \& VanArsdall, 2009). Arguably, animacy would be critical information in the human ancestral environment, where humans would be foraging animals and plants for survival. Animate beings may be a threat to be avoided or a prey to hunt.

People tend to transmit information relevant for sociality (e.g., Stubbersfield, Tehrani, \& Flynn, 2015). Gossip is a case in point. When Feinberg, Willer, Stellar, and Keltner (2012) had people witness someone's moral transgression and gave them an option to communicate to another person who is about to interact with the deviant, they spontaneously sent gossip about the deviant. Similarly, Peters and her colleagues have found people tend to transmit gossip about a person's moral character and regard those who transmit such information favorably (Peters \& Kashima, 2015). Gossip can provide information about the reputation of a person (E. R. Smith, 2014) and norms of a group (Foster, 2004), and is therefore beneficial for negotiating and regulating social relationships (i.e., whom to approach or avoid) as well as sustaining cooperation for collective action in their environmental niche (Feinberg, Willer, \& Schultz, 2014; Foddy, Platow, \& Yamagishi, 2009; Sommerfeld, Krambeck, Semmann, \& Milinski, 2007; Thomas, DeScioli, Haque, \& Pinker, 2014). 
Agency and sociality may be particularly meaning rich for humans, that is, agency and sociality information is rich with implications and help them make inferences because of their associations with other information. They have obvious links to competence and warmth (Fiske, Cuddy, \& Glick, 2006) in social perception, for instance, and such information may be preferentially transmitted. Cultural transmission of information about supernatural beings may be interpreted in this light. Boyer and Ramble (2001) showed that information about supernatural artefacts or persons that violate the ontological knowledge about the world (e.g., a man who could walk through a mountain) are recalled better than the information that does not violate it (e.g., a man who was slightly taller than a woman), suggesting that cultural information about supernatural beings is particularly likely to be retained by the human memory system. As such, supernatural beliefs and religion may be a natural part of human culture (Boyer \& Bergstrom, 2008).

Validity and Emotionality. Validity and emotionality of cultural information also appear to contribute to cultural transmission. On validity, cultural information is more likely produced if the sender believes it to be true and informative (Lyons \& Kashima, 2003), especially when the receivers lack the cultural information. Thus, in an instructional context, validity is a main driver, presumably because objectively valid information helps its possessors to adapt and survive.

Socially validated cultural information is also more likely to be transmitted. According to Echterhoff et al. (2009), when the sender and receiver establish that they have similar psychological reactions to given information, it is seen to constitute their shared reality. Bratanova and Kashima (2014) found that the senders who established their shared reality about information with their audience tended to repeat the same information to others, further disseminating it. Social validation can be facilitated by allowing the sender and receiver to communicate bidirectionally (e.g., Tan \& Fay, 2011) as in conversation, and 
giving receivers an opportunity to obtain information from multiple sources (e.g., Eriksson \& Coultas, 2012). Indeed, the latter has been found to contribute to cumulative culture (Muthukrishna, Shulman, Vasilescu, \& Henrich, 2014). This suggests that even misinformation may form part of a culture if it is socially validated - a critical contemporary issue awaiting further investigation (Lewandowsky, Ecker, \& Cook, 2017).

Emotive information is more likely to be transmitted than non-emotive information. As Rimé (2009) argued, this may be because the transmission of emotive information can help its senders to regulate their own emotions. By sharing information that instigates negative emotions, the senders can often down-regulate their emotions with the help of the receivers; conversely, they can savour their positive emotions by transmitting positively emotive information. Although some studies have found an advantage for negativelyvalenced information (Bebbington, MacLeod, Ellison, \& Fay, 2017; Brennan, Durkin, Wakefield, \& Kashima, 2016), others have not (Stubbersfield, Tehrani, \& Flynn, 2017). Berger's (2011) experiments suggest that it is arousal per se that drives emotive cultural transmission. When he had participants jog on the spot for a minute and gave a newspaper article in an ostensibly unrelated task, the joggers were more likely than those who did not jog to transmit the news to others. Social transmission of emotive information occurs on the internet as well. Heath, Bell, and Sternberg (2001) found that the more disgusting urban legends are (e.g., animal parts in a popular fast food restaurant), the more widespread on the internet they are, although this was not the case in India (Eriksson, Coultas, \& de Barra, 2016). Berger and Milkman (2012) found evidence for emotiveness as a predictor of online information sharing.

Context of Cultural Transmission. First, contextual prominence facilitates the transmissibility of information. Cultural information primed by environmental cues (e.g., artefacts) in the context tend to be transmitted (Berger \& Heath, 2005). For instance, Oishi, 
Kesebir, Eggleston, and Miao (2014) found that when students had many environmental cues of hedonism in their environment, i.e., party advertisements on campus, they were increasingly likely to transmit a hedonic story about a fun loving student than a eudaimonic story about a student in search of meaning in life.

Second, according to A. E. Clark and Kashima's (2007) situated functional model, of particular importance is social context - whether informativeness or social coordination is a prominent goal for cultural transmission. Cultural information inconsistent with the senders' and receivers' common ground (CG) is likely to be novel and therefore informative, but also not socially connective because it can signal a difference between the sender and receiver. This may incur a social cost because it can disrupt smooth conversational flow (on the importance of conversational flow, see Koudenburg, Postmes, \& Gordijn, 2017). In contrast, cultural information consistent with the common ground is uninformative, but likely to be meaning rich and socially connective because of its emphasis on sender-receiver similarity (i.e., "we are on the same wavelength") - "weness" and cultural identity. In other words, the sender faces a dilemma in cultural transmission whether to send novel but socially disconnecting information, or to send old but socially connective information. Depending on which is more important - informativeness or connectivity - different types of information are likely to be transmitted.

Thus, in the typical social context where there is no strong need to be informative, common ground consistent (CGC) information is more likely to be transmitted than common ground inconsistent (CGI) information. This is in accordance with what Bartlett (1932) called conventionalization in serial reproduction, i.e., serially transmitted information becomes more conventional in form and content as it is passed along. Analogously, assuming that culturally shared stereotypes are seen to be in most people's common ground, stereotype consistent information is generally more likely to be transmitted than stereotype inconsistent 
information (Hunzaker, 2016; Kashima, Lyons, \& Clark, 2013). Stereotype consistent information was seen to be more socially connective, but less informative than information inconsistent with stereotypes, and more likely to be transmitted and passed along down the serial reproduction chain than informative information. However, this CGC bias was reduced when the participants were led to believe that their community did not endorse related cultural stereotypes, that is, reducing perceptions of common ground (A. E. Clark \& Kashima, 2007).

More generally, in the typical social context socially connective information tends to be transmitted (A. E. Clark \& Kashima, 2007). So, information that is socially desirable (Bergsieker, Leslie, Constantine, \& Fiske, 2012; Schaller \& Conway, 1999), prominent (Fast, Heath, \& Wu, 2009), and socially beneficial for ingroup solidarity (Lee, Gelfand, \& Kashima, 2014) is likely transmitted presumably due to its social connectivity. Arguably, collectivist values are socially connective, and Schönpflug (2001) found that collectivist values (e.g., traditionalism, conformism, security) are more likely to be vertically transmitted from fathers to sons than individualist values (e.g., self-direction, stimulating life, hedonism) among Turkish in Turkey and Germany. Phalet and Schönpflug (2001) also reported a vertical transmission of family collectivist attitudes among Turkish families in Germany and Turkish and Moroccan families in the Netherlands. Sabatier and Lannegrand-Willems (2005) found a similar transmission pattern in three generations of French women. However, as the importance of informativeness increases in the context of cultural transmission, CGI information is more likely to be transmitted (Goodman, Webb, \& Stewart, 2009; Lyons \& Kashima, 2003).

Summary. Micro-level cultural dynamics are driven by the interdependent cognitive and communicative processes. Generally, cultural information more adaptive for the sender and receiver individually and their ingroup collectively appear to be more likely to be 
transmitted. Although what information is adaptive depends on the natural and human made environments, common ground within a population appears to be a significant factor in micro-cultural dynamics. Once cultural information is established as part of the population's common ground, it tends to perpetuate itself.

\section{Micro-Macro Dynamics}

Cultural information that is more likely transmitted in micro-level interactions is likely to increase its prevalence in a population (Schaller, Conway III, \& Tanchuk, 2002), and thus micro-level cultural dynamics would generate macro-level cultural trajectories in the long run. However, precisely how micro-to-macro linkages occur is often difficult to ascertain. A promising approach is to use formal analytical or agent-based simulation models. Here, we selectively review three broad approaches to modelling links between micro- and macro-level cultural dynamics in psychology.

Cultural Dissemination Models. In social psychology, models of social influence have been used to explain macro-level cultural phenomena such as polarization of public opinion (Abelson \& Bernstein, 1963) and spatial clustering, i.e., people with the same attitude tend to be close together in space (Andrzej Nowak, Szamrej, \& Latané, 1990). Indeed, people with similar attitudes tend to cluster together in geographical space (e.g., Latané \& L'Herrou, 1996) and in social networks (DiFonzo et al., 2013). However, because these models capture only one cultural element (i.e., an opinion on one issue), they cannot explain a cultural patterning. That is to say, cultural elements cannot be considered in isolation, but they often show a configural pattern.

Axelrod (1997) introduced a model that could explain polarization, spatial clustering, and cultural patterning. According to his model, an agent has multiple cultural features (e.g., religion, political orientation, etc.), each of which can take one of multiple possible traits 
(e.g., Christianity, Islam, Buddhism, etc.). This latter property was called the scope of cultural possibilities. Agents are placed on a grid, and interact with their neighbours by the following simple principles: (1) an agent dyadically interacts with another agent that shares some cultural elements (i.e., unless there is some cultural commonality, two agents cannot interact) and (2) when they interact, one of the dissimilar cultural elements becomes the same. Note that this algorithm embodies some basic principles of grounding, i.e., common ground (cultural commonality) enables and facilitates grounding and adoption (cultural transmission). If all agents start with random cultural vectors and keep interacting with each other, the population settles into a stable state where no further change can occur, i.e., all neighboring agents have identical or completely different cultural vectors. Axelrod's simulations showed that a population of agents settles to either monocultural state (all agents have the same cultural vector) or multicultural state (agents with the same cultural vector form a spatial cluster). Intriguingly, a multicultural state was likely with a greater scope of cultural possibilities.

The Axelrod model has been extended in many ways (for a review, see Kashima, Kirley, Stivala, \& Robins, 2017). For instance, monoculture is likely to ensue if cultural transmission is inaccurate (i.e., cultural learning is error prone: Klemm, Eguíluz, Toral, \& San Miguel, 2003a), or if spatially separated neighbours are linked by long-distance social network ties (Klemm, Eguíluz, Toral, \& San Miguel, 2003b; this can form a small world network). In contrast, contrary to intuition, an inclusion of global mass media effects (González-Avella et al., 2006; González-Avella, Cosenza, \& Tucci, 2005) and descriptive norm effects (Shibanai, Yasuno, \& Ishiguro, 2001) increases the tendency towards multicultural states. More generally, Flache and Macy (2011) showed that the Axelrod model with multilateral social influence (i.e., agents interact with multiple neighbors at the same time rather than dyadically) effects strong local convergence, sustaining multicultural states 
even with error prone cultural transmission. More recent extensions began to explore the effect of structure in cultural space. Valori, Picciolo, Allansdottir, and Garlaschelli (2012) used actual cultural vectors as measured by surveys as a starting point, showing that this has again increased the tendency towards multicultural state.

Evolutionary Game Theory. If cultural transmission tends to favour adaptive cultural information as we noted earlier, the formulations described so far seem to be deficient in that they do not explicitly model the adaptiveness of the cultural information. Evolutionary perspectives can complement this deficiency (Boyd \& Richerson, 1985; Cavalli-Sforza \& Feldman, 1981), and evolutionary game theory (e.g., Axelrod \& Hamilton, 1981; Maynard Smith, 1982) has been particularly influential in theoretical analyses of the evolution of cooperation. Because the complexity and volume of the literature (for reviews, see e.g., Chudek \& Henrich, 2011; Rand \& Nowak, 2013) far exceeds the scope of this brief review, we discuss the basic principles of this approach primarily based on M. A. Nowak (2006) to the extent it is helpful for subsequent discussion.

In simple applications, agents have one of two strategies when they interact with other agents: cooperation or defection. Nowak (2006) defined cooperation as paying some cost to give benefit to the partner in a dyad, whereas defection as paying nothing and giving nothing. When agents interact with each other in a dyad, each agent receives a payoff as a function of the combination of the agents' strategies. Given Nowak's definition, the payoff structure constitutes a Prisoners' Dilemma. If both agents cooperate, each agent gains more than if they both defect. However, if an agent defects, it gains more than if it cooperates, regardless of what its partner does. The payoff that an agent receives determines its fitness. The strategy of an agent with a greater fitness is more likely to be transmitted to the next generation. If a population of co-operators and defectors interact with each other randomly and transmit their strategies to the next generation, the population will eventually be all defectors. This is 
because, on the average, defectors will have a greater fitness than co-operators at any point in time, and therefore defectors will dominate.

However, many mechanisms have been shown to enable co-operators to survive (see Table 2). Many of the mechanisms can be shown to modify the payoff structure of the interaction, so that cooperation becomes more beneficial than defection under some circumstances (Taylor \& Nowak, 2007). One of the most robust mechanisms is assortment (e.g., West, Griffin, \& Gardner, 2007) - if co-operators assort themselves with other cooperators, they have a better chance of survival even if the environment is such that cooperation is difficult to sustain (e.g., the situation is characterized by a Prisoners' Dilemma). Partner selection (Baumard, Andre, \& Sperber, 2013) is a way of achieving assortment. For instance, kin selection is a partner selection based on genetic relatedness - by cooperating with genetically closely related others, one's genetic information is likely to be transmitted to the next generation (Hamilton, 1964). Many others involve reciprocity reciprocation of cooperation - one cooperates if one's partner cooperates (direct reciprocity; e.g., Trivers, 1971), has a good reputation to have cooperated in the past (indirect reciprocity; e.g., Nowak \& Sigmund, 1998), and is embedded in an interconnected social network (Ohtsuki, Hauert, Lieberman, \& Nowak, 2006).

Table 2: Mechanisms for the Evolution of Cooperation

\begin{tabular}{|c|c|}
\hline Type & Summary \\
\hline Kin Selection $^{\mathrm{a}}$ & Cooperate with a kin \\
\hline Direct Reciprocity ${ }^{\mathrm{a}}$ & Cooperate if partner cooperates \\
\hline Indirect Reciprocity ${ }^{\mathrm{a}}$ & Cooperate with good reputation \\
\hline Network & Cooperate within a social network \\
\hline Reciprocity $^{\mathrm{a}}$ & \\
\hline Attribute-based $^{\mathrm{b}}$ & Cooperate if partner shares attribute \\
\hline Group Selection $^{\mathrm{a}}$ & Cooperate to better adapt to environment or to outcompete outgroup \\
\hline Institution $^{\mathrm{c}}$ & $\begin{array}{l}\text { Cooperate if partner shares institution with power to reward } \\
\text { cooperation or punish non-cooperation }\end{array}$ \\
\hline
\end{tabular}

Note: ${ }^{a}$ Nowak (2006); ${ }^{b}$ Riolo et al. (2001); ${ }^{\mathrm{c}}$ Sigmund et al., 2010). 
In other cases, reciprocity is not required. In attribute-based cooperation, one cooperates with another who shares the same attribute (e.g., ethnicity, language, religion), which defines a social category. If agents with the same attribute tend to mutually cooperate, cooperation can survive (e.g., Riolo, Cohen, \& Axelrod, 2001) although it cannot sustain cooperation if the attribute can be easily faked. Cues that signal a shared culture can act as an attribute that sustains cooperation (Stivala, Kashima, \& Kirley, 2016). Group selection is based on the idea that groups with more co-operative members can survive better in a hostile environment or outcompete their outgroups (e.g., for a recent systematic statement of this position, see Richerson et al., 2016). Institutionalized mechanisms that monitor individuals' actions, and reward cooperation and punish defection (e.g., Sigmund, De Silva, Traulsen, \& Hauert, 2010) can also sustain cooperation. Obvious examples are police, court, and other mechanisms of law enforcement (punishment) and conferment of medals, decorations, and other forms of official recognitions of social contribution (reward). As we discuss later, we believe assortment and partner selection are intimately linked to macro-level cultural dynamics of collectivism.

Iterated Learning. The approaches discussed so far have used broad theoretical frameworks to explain global characteristics of macro-level cultural phenomena such as polarization, spatial clustering, cultural patterning, and the very existence of cooperation among humans based on micro-level social processes. Although there are some exceptions, the models are typically postulated to provide proof that the basic principles are sufficient to explain the observed cultural phenomena. However, they do not usually investigate how the process of transmission itself (rather than the mechanisms for selection or adaptation) affects the evolution of cultural information. Finally, their focus is usually on the phenomena involved (e.g., polarization) rather than the outcome of that phenomenon on an informational level (e.g., the content and nature of the systems that emerge). The iterated learning 
framework, which grew primarily out of a desire to better understand language evolution, fills some of these gaps.

Iterated learning first emerged in the early 2000 s as the method of serial reproduction applied to language evolution (Kirby, 2001). The central idea conceptualises cultural transmission as a process in which behaviour arises in one individual (or generation) and then is learned by subsequent individuals (or generations) who then similarly provide behaviour for the next individuals (generations) in the chain to learn from. One of the first application of iterated learning demonstrated that the process of transmission itself-not just the psychological or cultural fitness landscape - could shape the nature of language evolution (Kirby, 2001). For instance, the presence of a linguistic bottleneck (a constraint on the quantity or quality of information flow) in combination with some pressure for expressiveness (or meaning richness) results in compositional languages in which meaning depends in part on the rules for combining words rather than only the words themselves; either pressure alone does not ( Kirby, Tamariz, Cornish, \& Smith, 2015).

The explanatory power of the iterated learning as a framework was greatly enhanced by subsequent theoretical work demonstrating that the limiting behaviour of the chains could be mathematically characterised under some assumptions. For instance, Griffiths and Kalish (2007) showed that under certain assumptions the end point of evolution depends only on the learners' prior expectations and the size of the bottleneck. In general, it is possible to draw deep parallels between iterated learning and models of biological evolution (Suchow, Bourgin, \& Griffiths, 2017).

These theoretical results increase the utility of the iterated learning framework as an explanatory mechanism for understanding the pressures involved in macro-cultural dynamics. Iterated learning designs have demonstrated that the process of transmission "smooths out" or regularizes linguistic variability, even though individual learners may themselves have weak 
tendencies to regularize (Smith \& Wonnacott, 2010), though this depends somewhat on population structure and the capabilities of the learners (Smith et al., 2017). Iterated learning has been used to explore a variety of other phenomena, including how transmission combine with the nature of human memory to create languages with sequential structure (Cornish, Dale, Kirby, \& Christiansen, 2017), how transmission affects the lexicalization of pragmatic inferences (Brochhagen, Franke, \& van Rooij, 2016), and how it affects regularities in nonlinguistic domains such as music and rhythm (Ravignani, Delgado, \& Kirby, 2017).

Additional insight is possible by analysing how changing the mathematical assumptions within iterated learning alters the convergence behaviour of the overall system. For instance, if one presumes that the learners transmit information not only based on what they have learned, but also incorporating their goals and the environment they live in, the resulting "language" now reflects world structure rather than priors alone (Perfors \& Navarro, 2014). If people do not all share the same prior beliefs, the eventual population distribution of cultural information is disproportionately affected by people with more extreme priors (Navarro, Perfors, Kary, Brown, \& Donkin, 2017). The systematic evaluation of what happens when these mathematical assumptions change - and which assumptions best describe people and our world - opens up many new areas of research.

Beyond iterated learning, Bayesian and other quantitative analyses have also been used productively to study linguistic and cultural evolution by quantitatively analysing the extent to which existing systems appear to have been selected for or adapted in some way. For instance, word order universals and near-universals across the worlds' languages may reflect informational pressures during transmission (Futrell, Mahowald, \& Gibson, 2015; Maurits, Perfors, \& Navarro, 2010). In general, many features of human languages appear to have emerged out of trade-off between pressures that favour simplicity, like transmission, and pressures that favour complexity, like expressiveness (Christiansen \& Chater, 2015; 
Kirby et al., 2015). This trade-off is evident in different ways in features as diverse as graphical symbol systems (Garrod, Fay, Lee, Oberlander, \& Macleod, 2007), word frequency, length, and complexity (Piantadosi, Tily, \& Gibson, 2011), and many different kinds of categorisation systems (see Kemp et al., 2018 for an overview). This sort of quantitative research is complementary to iterated learning alone, since it investigates the outcome of the evolutionary process of cultural transmission and selection while iterated learning focuses on the process itself. Together, they help us to work towards a more complete picture of how macro-level human cultural products like language emerge through micro-level features of human cognition and communication.

Summary. Overall, each approach brings distinct components to the problem of linking the micro to the macro. The cultural dissemination models provide an understanding of broad transmission and social network dynamics, evolutionary game theory helps to explicate the importance of adaptation in the form of cost and benefit analysis, and the iterated learning framework and associated Bayesian models provide a theoreticallygrounded method for analysing how different selective pressures have distinct effects on the product of cultural evolution. Despite the insights provided by each approach, they are yet to be integrated within a comprehensive theoretical and modelling framework.

\section{Macro-Cultural Dynamics: Is there a global trend from collectivism to individualism?}

Through the cross-level linkage, micro-level cultural dynamics aggregate to effect macro-level cultural dynamics, i.e., the trajectories of cultural change over time. Although there is a growing literature on cultural change on a variety of psychological constructs, we will focus on research surrounding the hypothesis that cultures have been moving from collectivism towards individualism over the past decades. This focus reflects the centrality of individualism and collectivism in culture and psychology, and social sciences more generally. 
The thesis distantly echoes Tönnies's (1963) characterization of cultural change in the $19^{\text {th }}$ century Europe from traditional Gemeinschaft (community) to modern Gesellschaft (society). His basic tenets are discernible in Durkheim (1933) and modernization theory (Knöbl, 2003), and more recently revived by Greenfield (2009).

Reconceptualizing Individualism and collectivism. Here, we conceptualize individualism and collectivism as two broad classes of cultural ideas and practices.

Individualism(s). The defining characteristic of individualism is often regarded as the independent self (Markus \& Kitayama, 1991; Triandis, 1995); however, the notion of independent self is itself highly multi-faceted. Vignoles and his colleagues (Vignoles et al., 2016) identified seven largely orthogonal dimensions of independent self in arguably the most comprehensive cross-cultural investigation of self-concepts to date, encompassing 55 cultural groups from a variety of world regions including Sub-Sahara Africa (see Table 3). We use the term individualism as a set of cultural ideas and practices consistent in meaning with the conception of the person as an independent being in these ways. In Vignoles et al.'s study, no culture is high in all these aspects of independent self, casting uncertainty over the hypothesis that a culture changes uniformly in all aspects of individualism.

Table 3: A variety of individualisms based on Vignoles et al. (2016)

\begin{tabular}{ll}
\hline Dimension & Brief Description \\
\hline Self-other difference & Defining oneself in terms of differences from others \\
Self-containment & Experiencing own feelings independently of others \\
Self-direction & Making decisions on one's own \\
Self-reliance & Relying on oneself \\
Consistency & Acting consistently across situations \\
Self-expression & Expressing own feelings \\
Self-interest & Emphasizing own interests and accomplishments \\
\hline
\end{tabular}

Collectivism(s) as cultural practices of assortment. Collectivism can be regarded as the cultural practice of partner selection (Baumard, Andre, \& Sperber, 2013), i.e., what type of people are selected as a partner of social interaction with whom one cooperates. Recall that partner selection is a mechanism of assortment that can help sustain cooperation (see Table 
2). Different collectivisms encourage selection of different types of partners. Kin-, network-, and attribute-based collectivisms are ideas and practices of interacting and cooperating with others of the same kin (i.e., kinsmen should help each other), one's partner's partner (i.e., my friend's friend is my friend), and others that share the same attribute such as a race and religion, respectively. Network- and attribute-based partner selection practices closely resemble what Brewer and Chen (2007) called relational and group collectivism. Relational collectivism emphasizes the maintenance of harmonious interpersonal relationships, whereas group collectivism emphasizes the significance of a social category based membership. The former tends towards a cohesive and tightly knit small group, whereas the latter enables the formation and maintenance of a large-scale collective that shares a social identity and can also act as a basis for ingroup-outgroup differentiation and competition. Thus, the latter can act as a basis of group selection.

A special subtype of attribute-based collectivism is nation-state based. According to Giddens (1990), nation-states are institutions of governance that combine a highly sophisticated system of surveillance with a powerful means of violence (i.e., military, police). In idealized form, they combine with democracy as a mode of government selection and the rule of law as a mode of social regulation. Among other things, nation-states provide mechanisms of social control that ensure individuals' mutual cooperation under their jurisdiction. The nation-states can use their powers to sanction individuals who violate their regulatory frameworks, and therefore under this assurance, individuals can maintain an expectation of cooperation from others under state jurisdiction. In this sense, nation-states provide not only social categories whose membership can act as an attribute for attributebased partner selection, but also a built-in mechanism of social control to maintain cooperation under its jurisdiction. Those under a nation-state's jurisdiction constitute a civil society and its members are expected to be trusted to cooperate with each other and 
coordinate their actions under the same social regulatory umbrella. We interpret generalized trust (i.e., people can be generally trusted) as an indication of civil society-based collectivism.

Caveats. This conceptualization of individualism and collectivism does not imply that they are opposite ends of a continuum. Declining collectivism does not imply increasing individualism, or vice versa. Therefore, declining kin-based collectivism (e.g., increasing divorce rate, decreasing household size) for instance does not necessarily mean increasing individualism (cf. Grossmann \& Varnum, 2015). The finding that generalized trust tends to be high in individualist countries (Yamagishi, 2017) is a prominent example. When a nationstate's institutions are functioning well (especially their institutions to maintain social order), its citizens' generalized trust increases (Rothstein \& Stolle, 2008), and may facilitate greater coordination of their political, economic and societal activities. These societies have tended to become prosperous, and their wealth appears to have enabled some aspects of individualism (especially self-expressiveness; see Inglehart \& Baker, 2000) to flourish. Under these circumstances, some aspects of individualism do not interfere with the sustenance of cooperation because nation-states' impersonal institutions are always there to enforce cooperation and ensure a means of survival. Nonetheless, psychological tensions that may exist between attribute-based collectivism and individualism are well captured by social psychological theories of collective self (e.g., Brewer, 1991; Turner, 1987).

Cultural Changes around the World. A sizable body of empirical research has documented cross-temporal changes in the population distribution of cultural ideas and practices (for recent reviews, see Hamamura, 2017; Varnum \& Grossmann, 2017). This is in no small part thanks to the availability of large archival records such as governmental records and digitized books (Google Ngram; Michel et al., 2011), long-running surveys (e.g., World Value Survey, Monitoring the Future, General Social Survey), and decades of cumulative research in psychology (e.g., meta-analyses of published research). Together, these have 
enabled the use of multiple methods to investigate long-term macro-level cultural dynamics (Kashima, 2014).

$\boldsymbol{U S A}$. There is evidence of increasing individualism in terms of self-expression and self-interest in the United States. Increasing self-expressiveness can be seen in American parents' greater use of unique first names (Twenge, Abebe, \& Campbell, 2010). Increasing levels of self-interest can be seen from a stronger emphasis on self's accomplishments and interests as in higher levels of self-esteem (Twenge, Carter, \& Campbell, 2017; Twenge \& Campbell, 2001), self-enhancement (Twenge \& Campbell, 2008), and Narcissism (Twenge, Konrath, Foster, Campbell, \& Bushman, 2008; on possible regional and ethnic differences, see Twenge \& Foster, 2010). Although there are other indications of increasing individualism - increasing frequencies of first person singular pronouns (Twenge, Campbell, \& Gentile, 2013) and individualist words in US Ngram corpora (Greenfield, 2013; Grossmann \& Varnum, 2015; Twenge, Campbell, \& Gentile, 2012b) and in popular songs (DeWall, Pond, Campbell, \& Twenge, 2011) - it is at times difficult to ascertain which aspects of individualism they are tapping. Unambiguous evidence of increases in aspects of individualism such as self-reliance or consistency is scarce - in fact, there are some signs of waning self-reliance as seen in increasing external locus of control (Twenge, Zhang, \& Im, 2004).

Kin-based collectivism is weakening, as seen from value surveys (Hamamura, 2012; Santos, Varnum, \& Grossmann, 2017) and from changes in family practices such as divorce rate, household size, and frequencies of multigeneration household and people living alone (Grossmann \& Varnum, 2015; Hamamura, 2012). Additionally, several indicators suggest a decline in nation-state based collectivism in the US. This includes that Americans' generalized trust and confidence in institutions such as the government, political system, and judiciary have waned in the last half-century (Hamamura, 2012; Twenge, Campbell, \& 
Carter, 2014), and a decreased tendency in US presidential addresses to use the term "happy" to refer to the nation, as in the phrase "happy country" (Oishi, Graham, Kesebir, \& Galinha, 2013). Indeed, US citizens' confidence in democracy itself appears to have declined over time (Foa \& Mounk, 2016) maybe because "in recent years U.S. democracy has become appallingly dysfunctional" (Inglehart, 2016, p.19). The US population seems divided about this cultural change, with an increasing polarization towards both extreme conservativism and liberalism (Twenge, Honeycutt, Prislin, \& Sherman, 2016).

There are mixed trends in the endorsement of general collectivist values such as honouring obligation or obedience (Hamamura, 2012), as well as the frequency of collectivist words like obliged, obedience, or communal; some of these appear to have decreased (Greenfield, 2013; Grossmann \& Varnum, 2015) whereas one shows a steady trend over time (Twenge et al., 2012). Arguably, these concepts may be connected to kin-based and local community-based collectivism. We are not aware of evidence of declining race-based collectivism, for instance, in the USA.

East Asia. Hamamura (2017) suggested that traditional cultural elements have persisted or become even more prevalent despite some cultural change towards individualism in East Asia. On one hand, there is an increasing amount of discourse favouring individualism in many respects, with an increasing frequency of some self-other differentiating, self-directional, and self-expressive words in the Chinese Google Ngram corpus within the past two decades (Xu \& Hamamura, 2014; Zeng \& Greenfield, 2015; Zhang \& Weng, 2017). As well, Japanese parents use increasingly unique baby names (Ogihara et al., 2015). The endorsement of self-directional values (e.g., independence in child socialization) has increased in Japan (Hamamura, 2012; Santos et al., 2017) though stable in China (Santos et al., 2017). On the other hand, the cultural importance of individual rights appears to have declined in Japan (Hamamura, 2012) and the use of first person singular 
pronouns in China showed a complex pattern of ups and downs over time (Hamamura \& Xu, 2015). Similarly, bucking the trend of increasing individualism is self-interest as gauged by positive self-regard. Cross-temporal meta-analyses of Rosenberg's self-esteem reveal a declining trend in both China (Liu \& Xin, 2015; Xin, Niu, \& Chi, 2012) and Japan (Oshio, Okada, Mogaki, Namikawa, \& Wakita, 2014). Ogihara and his colleagues (Ogihara, 2016; Ogihara, Uchida, \& Kusumi, 2016) also found declining self-esteem over time in surveys of Japanese students and young adults.

On collectivism, Hamamura (2012) found mixed trends in Japan. Kin-based collectivist practices have declined in many ways - the rates of divorce and people living alone have increased, and household size has decreased. However, other indicators are less clear. Levels of unconditional respect for parents have declined and the importance of friends (presumably as opposed to family) have increased, but emphasis on family life (as opposed to work) has increased. This last trend may indicate a waning of company-based collectivism rather than a strengthening of kin-based collectivism, however. The importance of honouring obligation has also declined. Overall, levels of societal collectivism within Japan based on nation-states shows a complex pattern. Although those who regard their country as important and most people as trustworthy have decreased over time, a slightly differently worded question ("most people would not take advantage of you") shows a trend of greater endorsement over time.

In China, general collectivist discourse also shows mixed trends since the 1980s, when economic reforms began to take shape. On the one hand, the frequencies of collectivist words (Zeng \& Greenfield, 2015; Zhang \& Weng, 2017) and first person plural pronouns have decreased (Hamamura \& Xu, 2015). On the other hand, words and phrases that imply kin-based collectivism (e.g., family, parents) and those that China experts regard as traditionally important (e.g., doctrine of mean, Confucian ethics, filial piety, Chinese New 
Year) have increased in frequency (Xu \& Hamamura, 2014; Zhang \& Weng, 2017). Finally, there are some signs of weakening nation-state based collectivism. Words like democracy and patriotism have become less frequent over time (Xu \& Hamamura, 2014) and interpersonal trust has decreased (Xin \& Xin, 2017).

Other countries. Inglehart and Baker (2000) showed a general increase in selfexpression in $84 \%(32 / 38)$ of the countries they examined from 1980 to 1998 based on the World Value Survey. Santos et al. (2017) found an increasing trend in self-direction and selfexpression (importance of friends over family, independence in child socialization, and selfexpression) using World Value Survey and European Values Survey over a more recent period in 58\% (31/53) of the countries they examined, and an overall effect when aggregated across all countries. Germans are increasingly using individualist words (Younes \& Reips, 2017); research in a Mayan community in Mexico found an increase in skills for managing novel and self-expressive weaving patterns (Maynard, Greenfield, \& Childs, 2015). Although kin-based collectivism (divorce, household size, and living alone) declined in a majority of countries, there are exceptions in Asia (Bangladesh, Fiji, Malaysia), Africa (Burkina Faso, Cameroon, Malawi, Mali, Morocco, Zambia), and Central America (Costa Rica, Dominican Republic, Haiti; Santos et al., 2017).

Noteworthy exceptions can also be found in countries of the former Soviet Union such as Belarus, Estonia, Latvia, Lithuania, and Russia. These countries showed a decline in self-expression in Inglehart and Baker's analysis, and again showed no change, together with Ukraine, in Santos et al. Correspondingly, the frequency of individualist words over the period after the October Revolution (1917) up to the perestroika reforms (1985) showed only a slight, non-significant increase, although there was a strong increase from 1986 to 2009 (Skrebyte, Garnett, \& Kendal, 2016). 
Also intriguing is the finding that there does not appear to be any change in selfinterest (self-esteem) in Australia from 1978 to 2014 (Hamamura \& Septarini, 2017). This trend diverges from the US pattern despite Australia's general cultural similarity to the US. Hamamura and Septarini (2017) explained this in terms of American vertical vs. Australian horizontal individualism; Australia places a strong emphasis on egalitarianism while America emphasises distinguishing oneself from others in terms of competition, achievement, and power.

Why do cultures change? The socioeconomic environment appears to be a critical driver of cultural change, although the natural environment (e.g., pathogen, natural disasters) may also play some role (Grossmann \& Varnum, 2015; Santos et al., 2017). Socioeconomic development is high if a country is urbanized and populated by wealthy (high GDP per capita), better educated, and more skilled citizenry (Greenfield, 2013). Socioeconomically developed countries by this standard tend to be well established nation-states with democratic institutions, and Grossmann, Varnum, and their colleagues' (2015; Santos et al. 2017) work showed that socioeconomic development in this sense tends to increase individualism as measured by self-directiveness and self-expressiveness (also see Bianchi, 2016).

That said, other aspects of individualism may not show the same trend in all countries. Although wealth has increased in Australia, China, Japan, and the United States, only the USA has shown an increasing trend of self-interest as gauged by positive self-regard. There are other exceptions. Skrebyte et al. (2016) found that economic prosperity was associated with greater frequencies of collectivist ideas in Russia between 1961 and 1994. Broadly speaking, although Hofstede (1980) found a strong correlation between national wealth and individualism, this relationship is non-significant in some countries (Kashima \& Kashima, 2003), hinting at the presence of a factor that may moderate the effect of socioeconomic development on individualism. 
On the collectivism side, there is evidence that socioeconomic development decreases kin-based collectivist practices (Santos et al., 2017). However, this is moderated by climate stress. In countries with greater climate stress and more challenging natural environments, socioeconomic development reduces kin-based collectivist practices to a greater extent than in countries with less climate stress. In those countries with poor institutional support, kinbased cooperation may play a significant role in adapting to the natural environmental challenges; however, kin-based support may become less critical as the countries' infrastructure improves. In countries with optimal climate, kin-based collectivism appears to be relatively weak regardless. A socioeconomic development x climate stress interaction was not observed for individualist values. It is important to note that currently strong evidence exists only for declining kin-based collectivism, but not for other collectivisms, e.g., race- or religion-based collectivism.

Summary. The ongoing global change - the deepening globalization of marketdriven economy and concomitant change in the role of nation-states as an institutional framework - has had a powerful effect on culture. In general, these changes have made many countries more affluent but have also widened the wealth gap both between richer and poorer countries as well as within many countries. This may be interpreted in terms of an increasing selective pressure in favour of many, but not necessarily all, individualist ideas. One aspect of individualism, positive self-regard, appears to have increased in the USA, but not in East Asia or Australia, suggesting the presence of a moderating factor at play.

In terms of collectivism, kin-based collectivist practices of partner selection, as reflected in a traditional family structure, seems to have declined. There also appears to be a decrease in generalized trust, which is interpreted here as a nation-state and civil society based societal collectivism. Together with a sign of declining confidence in the existing institutional framework in the US (Twenge et al., 2014) and other countries around the world 
(Foa \& Mounk, 2017), the psychological underpinnings for the current nation-state based system of global governance may be waning. One of the factors that may play an important role here is economic inequality: although an average economic upturn tends to improve generalized trust, economic inequality tends to depress it, at least in the US (Twenge et al., 2014). If this is true about other countries, economic equality may be playing a significant role in the ongoing global cultural change.

\section{Concluding Comments and Future Directions}

The social psychology of cultural dynamics has accumulated a great deal of knowledge. At the micro-level, cultural information that is easier to produce, ground, interpret, or remember, and is therefore less costly or more rewarding for processing at the cognitive and social levels, is more likely to be culturally transmitted. On average, cultural information is especially likely transmitted if it is about agency or sociality, if it is emotive, if it is valid, and if it is generally meaning-rich.

Beyond the generalization that micro-level cultural transmission effects macro-level cultural trajectories, formal and agent-based models have served as the primary investigative tool for linking micro and macro cultural dynamics. Such approaches are useful in specifying the mechanisms sufficient to generate broad cultural phenomena such as polarization, spatial clustering, and cultural patterning, as well as to quantitatively evaluate the effects of competing pressures imposed by cognition and communication. Still, a great deal more remains to be done to understand these mechanisms and pressures, to yield more specific predictions about cultural phenomena of interest, and to combine these distinct approaches and thus leverage the explanatory power of each.

Finally, macro-level cultural changes have been examined in several countries across the world - primarily the United States, with some focus on other regions, especially East 
Asia. The working hypothesis that modern cultural change proceeds from collectivism to individualism has been tested using increasingly sophisticated and diverse methods, and global trends may indeed be described in broad terms as increasing individualism and declining collectivism. However, more detailed examinations show a number of exceptions and nuances, suggesting that a unilinear cultural change from collectivism to individualism is untenable.

Looking forward, three main issues stand out. First, there are a number of methodological issues surrounding cultural dynamics research (Kashima, 2014; Sun \& Ryder, 2016), including whether a significance test or an effect size should be a basis for inferring a macro-level cultural change (Trzesniewski \& Donnellan, 2010; Twenge \& Campbell, 2010) and statistical issues of autocorrelation and autoregression (Koplenig \& Müller-Spitzer, 2016).

Second, there need to be greater efforts to bring micro-level and micro-macro linkage research to bear on the macro-cultural dynamics, like individualism and collectivism. Exceptions are Imada and Yussen (2012) on collectivism and A. Nowak, Gelfand, Borkowski, Cohen, and Hernandez (2016) on culture of honor. Future research can be oriented towards further cross-fertilizations of different levels of analyses.

Third, of particular importance in the contemporary world are investigations about the mechanisms of cultural change. As we face the global challenges of the $21^{\text {st }}$ century, e.g., climate change and intergroup conflict, there is an increasing need for humanity to be able to harness our own culture, so as to better adapt to the changing natural and human-made environment (Kashima, 2016a). If cultural information in our common ground tends to perpetuate itself and socially transformative information that challenges the cultural status quo is harder to transmit (Connor et al., 2016), greater efforts need to be directed towards a better understanding of the mechanisms of the transmission, retention, and adoption of 
Cultural Dynamics 36

transformative cultural information. Behaviour change is critically important translational cultural dynamics research for the future (Wilson, Hayes, Biglan, \& Embry, 2014). 


\section{Acknowledgement}

The preparation of this article was facilitated by grants from the Australian Research Council (DP160102226 and DP160102231) to YK. 


\section{References}

Abelson, R. P., \& Bernstein, A. (1963). A computer simulation model of community referendum controversies. Public Opinion Quarterly, 27(1).

Acerbi, A., \& Bentley, R. A. (2014). Biases in cultural transmission shape the turnover of popular traits. Evolution and Human Behavior, 35(3), 228-236.

https://doi.org/10.1016/j.evolhumbehav.2014.02.003

Anderson, M. C., \& Bell, T. (2001). Forgetting our facts: The role of inhibitory processes in the loss of propositional knowledge. Journal of Experimental Psychology: General, 130(3), 544-570. https://doi.org/10.1037/0096-3445.130.3.544

Axelrod, R. (1997). The dissemination of culture: A model with local convergence and global polarization. Journal of Conflict Resolution, 41(2), 203-226. https://doi.org/10.1177/0022002797041002001

Axelrod, R., \& Hamilton, W. D. (1981). The Evolution of Cooperation. Science, 211(4489), 1390-1396. https://doi.org/10.1086/383541

Bartlett, F. C. (1932). Remembering: A Study in Experimental and Social Psychology. Cambridge, Social Psychology, 1-11. https://doi.org/10.1111/j.20448279.1933.tb02913.x

Baumard, N., Andre, J. B., \& Sperber, D. (2013). A mutualistic approach to morality: The evolution of fairness by partner choice. Behavioral and Brain Sciences, 36(1), 59-78. https://doi.org/10.1017/s0140525x11002202

Bebbington, K., MacLeod, C., Ellison, T. M., \& Fay, N. (2017). The sky is falling: evidence of a negativity bias in the social transmission of information. Evolution and Human Behavior, 38(1), 92-101. https://doi.org/10.1016/j.evolhumbehav.2016.07.004

Bentley, R. A., Hahn, M. W., \& Shennan, S. J. (2004). Random drift and culture change. Proceedings of the Royal Society of London, Series B, 271(1547), 1443-1450. 
https://doi.org/10.1098/rspb.2004.2746

Bentley, R. A., Lipo, C. P., Herzog, H. A., \& Hahn, M. W. (2007). Regular rates of popular culture change reflect random copying. Evolution and Human Behavior, 28(3), 151158. https://doi.org/10.1016/j.evolhumbehav.2006.10.002

Berger, J. (2011). Arousal increases social transmission of information. Psychological Science, 22(7), 891-893.

Berger, J., \& Heath, C. (2005). Idea habitats: How the prevalence of environmental cues influences the success of ideas. Cognitive Science, 29(2), 195-221. https://doi.org/10.1207/s15516709cog0000_10

Berger, J., \& Milkman, K. L. (2012). What Makes Online Content Viral? Journal of Marketing Research, 49(2), 192-205.

Bergsieker, H. B., Leslie, L. M., Constantine, V. S., \& Fiske, S. T. (2012). Stereotyping by omission: Eliminate the negative, accentuate the positive. Journal of Personality and Social Psychology, 102(6), 1214-1238. https://doi.org/10.1037/a0027717

Bianchi, E. C. (2016). American individualism rises and falls with the economy: Crosstemporal evidence that individualism declines when the economy falters. Journal of Personality and Social Psychology, 111(4), 567.

Boothby, E. J., Clark, M. S., \& Bargh, J. a. (2014). Shared Experiences Are Amplified. Psychological Science, 25(12), 2209-2216. https://doi.org/10.1177/0956797614551162 Boyd, R., \& Richerson, P. J. (1985). Culture and the Evolutionary Process. The Journal of Nervous and Mental Disease (Vol. 175). https://doi.org/10.1097/00005053-19870200000018

Boyer, P., \& Bergstrom, B. (2008). Evolutionary perspectives on religion. Annual Review of Anthropology, 37(1), 111-130. https://doi.org/10.1146/annurev.anthro.37.081407.085201 
Boyer, P., \& Ramble, C. (2001). Cognitive templates for religious concepts: Cross-cultural evidence for recall of counter-intuitive representations. Cognitive Science, 25(4), 535564. https://doi.org/10.1207/s15516709cog2504_2

Bratanova, B., \& Kashima, Y. (2014). The "saying is repeating" effect: dyadic communication can generate cultural stereotypes. J Soc Psychol, 154(2), 155-174. https://doi.org/10.1080/00224545.2013.874326

Brennan, E., Durkin, S. J., Wakefield, M., \& Kashima, Y. (2016). Why do smokers talk about antismoking campaigns? Predictors of the occurrence and content of campaigngenerated conversations. Health Communication, 21(1), 33-45. https://doi.org/10.1080/10410236.2016.1239301

Brewer, M. B. (1991). The social self: On being the same and different at the same time. Personality and Social Psychology Bulletin, 17(5), 475-482.

Brewer, M. B., \& Chen, Y. R. (2007). Where (who) are collectives in collectivism? Toward conceptual clarification of individualism and collectivism. Psychological REview, 114(1), 133-151. https://doi.org/10.1037/0033-295x.114.1.133

Brochhagen, T., Franke, M., \& van Rooij, R. (2016). Learning biases may prevent lexicalization of pragmatic inferences: a case study combining iterated (Bayesian) learning and functional selection. In Proceedings of the 38th Annual Conference of the Cognitive Science Society (pp. 2081-2086). Austin, TX: Cognitive Science Society. Buskell, A. (2017). What are cultural attractors? Biology \& Philosophy, 32(3), 377-394. https://doi.org/10.1007/s10539-017-9570-6

Carr, P. B., \& Walton, G. M. (2014). Cues of working together fuel intrinsic motivation. Journal of Experimental Social Psychology, 53(1), 169-184. https://doi.org/10.1016/j.jesp.2014.03.015

Cavalli-Sforza, L. L., \& Feldman, M. W. (1981). Cultural transmission and evolution. 
Princeton, NJ: Princeton University Press.

Christiansen, M. H., \& Chater, N. (2015). The Now-or-Never bottleneck: A fundamental constraint on language. Behavioral and Brain Sciences.

https://doi.org/10.1017/S0140525X1500031X

Chudek, M., \& Henrich, J. (2011). Culture-gene coevolution, norm-psychology and the emergence of human prosociality. Trends in Cognitive Sciences, 15(5), 218-226. https://doi.org/10.1016/j.tics.2011.03.003

Claidiere, N., Scott-Phillips, T. C., \& Sperber, D. (2014). How Darwinian is cultural evolution? Philosophical Transactions of the Royal Society B. Biological Sciences, 369, 20130368. https://doi.org/http://dx.doi.org/10.1098/rstb.2013.0368

Clark, A. E., \& Kashima, Y. (2007). Stereotypes help people connect with others in the community: a situated functional analysis of the stereotype consistency bias in communication. Journal of Personality and Social Psychology, 93(6), 1028-39. https://doi.org/10.1037/0022-3514.93.6.1028

Clark, H. H. (1996). Using language. New York, NY: Cambridge University Press.

Coman, A., Manier, D., \& Hirst, W. (2009). Forgetting the unforgettable through conversation: Socially shared retrieval-induced forgetting of September 11 memories. Psychological Science, 20(5), 627-633.

Connor, P., Harris, E., Guy, S., Fernando, J., Shank, D. B., Kurz, T., Bain, P. G., \& Kashima, Y. (2016). Interpersonal communication about climate change: How messages change when communicated through simulated online social networks. Climatic Change, 136(34), 463-476.

Cornish, H., Dale, R., Kirby, S., \& Christiansen, M. H. (2017). Sequence memory constraints give rise to language-like structure through iterated learning. PLoS ONE, 12(1). https://doi.org/10.1371/journal.pone.0168532 
Cuc, A., Ozuru, Y., Manier, D., \& Hirst, W. (2006). On the formation of collective memories: The role of a dominant narrator. Memory \& Cognition, 34(4), 752-762. https://doi.org/10.3758/bf03193423

Dawkins, R. (1976). The selfish gene. Oxford, UK: Oxford University Press.

DeWall, C. N., Pond, R. S., Campbell, W. K., \& Twenge, J. M. (2011). Tuning in to Psychological Change: Linguistic Markers of Psychological Traits and Emotions Over Time in Popular US Song Lyrics. Psychology of Aesthetics Creativity and the Arts, 5(3), 200-207. https://doi.org/10.1037/a0023195

DiFonzo, N., Bourgeois, M. J., Suls, J. M., Homan, C., Stupak, N., Brooks, B., ... Bordia, P. (2013). Rumor clustering, consensus, and polarization: Dynamic social impact and selforganization of hearsay. Journal of Experimental Social Psychology, 49(3), 378-399. https://doi.org/10.1016/j.jesp.2012.12.010

Durkheim, E. The division of labor in society (G. Simpson, Trans.). New York: Free Press. Echterhoff, G., Higgins, E. T., Kopietz, R., \& Groll, S. (2008). How communication goals determine when audience tuning biases memory. Journal of Experimental Psychology: General, 137(1), 3-21. https://doi.org/10.1037/0096-3445.137.1.3

Echterhoff, G., Higgins, E. T., \& Levine, J. M. (2009). Shared reality: Experiencing commonality with others' inner states about the world. Perspectives on Psychological Science, 4(5), 496-521. https://doi.org/10.1111/j.1745-6924.2009.01161.x

Eriksson, K., \& Coultas, J. C. (2012). The advantage of multiple cultural parents in the cultural transmission of stories. Evolution and Human Behavior, 33(4), 251-259. https://doi.org/10.1016/j.evolhumbehav.2011.10.002

Eriksson, K., Coultas, J. C., \& de Barra, M. (2016). Cross-cultural differences in emotional selection on transmission of information. Journal of Cognition and Culture, 16(1-2), 122-143. https://doi.org/10.1163/15685373-12342171 
Fast, N. J., Heath, C., \& Wu, G. (2009). Common ground and cultural prominence: How conversation reinforces culture. Psychological Science, 20(7), 904-911. https://doi.org/10.1111/j.1467-9280.2009.02387.x

Feinberg, M., Willer, R., \& Schultz, M. (2014). Gossip and ostracism promote cooperation in groups. Psychol Sci, 25(3), 656-664. https://doi.org/10.1177/0956797613510184

Feinberg, M., Willer, R., Stellar, J., \& Keltner, D. (2012). The virtues of gossip: Reputational information sharing as prosocial behavior. Journal of Personality and Social Psychology, 102(5), 1015-1030.

Fincher, C. L., Thornhill, R., Murray, D. R., \& Schaller, M. (2008). Pathogen prevalence predicts human cross-cultural variability in individualism/collectivism. Proceedings Biological Ssciences, 275(1640), 1279-1285. https://doi.org/10.1098/rspb.2008.0094

Fiske, S. T., Cuddy, A. J. C., \& Glick, P. (2006). Universal dimensions of social cognition: Warmth and competence. Trends in Cognitive Sciences, 11(2), 77-83.

Flache, A., \& Macy, M. W. (2011). Local Convergence and Global Diversity: From Interpersonal to Social Influence. Journal of Conflict Resolution, 55(6), 970-995. https://doi.org/10.1177/0022002711414371

Foa, R. S., \& Mounk, Y. (2016). The democratic disconnect. Journal of Democracy, 27(3), 5-17. https://doi.org/10.1353/jod.2016.0049

Foa, R. S., \& Mounk, Y. (2017). The signs of deconsolidation. Journal of Democracy, 28(1), 5-15. https://doi.org/10.1353/jod.2017.0000

Foddy, M., Platow, M., \& Yamagishi, T. (2009). Group-based trust in strangers: The role of stereotypes and expectations. Psychological Science, 20(4), 419-422. https://doi.org/10.1111/j.1467-9280.2009.02312.x

Foster, E. K. (2004). Research on gossip: Taxonomy, methods, and future directions. Review of General Psychology, 8(2), 78-99. https://doi.org/10.1037/1089-2680.8.2.78 
Futrell, R., Mahowald, K., \& Gibson, E. (2015). Large-scale evidence of dependency length minimization in 37 languages. Proceedings of the National Academy of Sciences, 112(33), 10336-10341. https://doi.org/10.1073/pnas.1502134112

Garrod, S., Fay, N., Lee, J., Oberlander, J., \& Macleod, T. (2007). Foundations of representation: where might graphical symbol systems come from? Cognitive Science, 31(6), 961-987. https://doi.org/10.1080/03640210701703659

Gelfand, M. J., Raver, J. L., Nishii, L., Leslie, L. M., Lun, J., Lim, B. C., ... Yamaguchi, S. (2011). Differences between tight and loose cultures: A 33-nation study. Science, 332(6033), 1100-1104. https://doi.org/10.1126/science.1197754

Giddens, A. (1990). The consequences of modernity. Stanford, CA: Stanford University Press.

González-Avella, J. C., Cosenza, M. G., \& Tucci, K. (2005). Nonequilibrium transition induced by mass media in a model for social influence. Physical Review E, 72(6), 065102(R). https://doi.org/10.1103/PhysRevE.72.065102

González-Avella, J. C., Eguíluz, V. M., Cosenza, M. G., Klemm, K., Herrera, J. L., \& San Miguel, M. (2006). Local versus global interactions in nonequilibrium transitions: A model of social dynamics. Physical Review E, 73(4), 46119. https://doi.org/10.1103/PhysRevE.73.046119

Goodman, R. L., Webb, T. L., \& Stewart, A. J. (2009). Communicating stereotype-relevant information: is factual information subject to the same communication biases as fictional information? Pers Soc Psychol Bull, 35(7), 836-852. https://doi.org/10.1177/0146167209334780

Greenfield, P. M. (2009). Linking social change and developmental change: shifting pathways of human development. Developmental Psychology, 45(2), 401-418. https://doi.org/10.1037/a0014726 
Greenfield, P. M. (2013). The changing psychology of culture from 1800 through 2000. Psychological Science, 24(9), 1722-1731. https://doi.org/10.1177/0956797613479387

Griffiths, T. L., \& Kalish, M. L. (2007). Language evolution by iterated learning with Bayesian agents. Cognitive Science, 31(3), 441-480.

https://doi.org/10.1080/15326900701326576

Grossmann, I., \& Varnum, M. E. W. (2015). Social structure, infectious diseases, disasters, secularism, and cultural change in America. Psychological Science, 26(3), 311-324.

Hamamura, T. (2012). Are cultures becoming individualistic? A cross-temporal comparison of individualism-collectivism in the United States and Japan. Personality and Social Psychology Review, 16(1), 3-24. https://doi.org/10.1177/1088868311411587

Hamamura, T. (2017). A cultural psychological analysis of cultural change. Asian Journal of Social Psychology. https://doi.org/10.1111/ajsp.12194

Hamamura, T., \& Septarini, B. G. (2017). Culture and Self-Esteem Over Time: A CrossTemporal Meta-Analysis Among Australians, 1978-2014. Social Psychological and Personality Science, 1948550617698205.

Hamamura, T., \& Xu, Y. (2015). Changes in Chinese culture as examined through changes in personal pronoun usage. Journal of Cross-Cultural Psychology, 46(7), 930-941.

Hamilton, W. D. (1964). The genetical evolution of social behaviour. I. Journal of Theoretical Biology, 7(1), 1-16. https://doi.org/10.1016/0022-5193(64)90038-4

Heath, C., Bell, C., \& Sternberg, E. (2001). Emotional selection in memes: The case of urban legends. Journal of Personality and Social Psychology, 81(6), 1028-1041. https://doi.org/10.1037/0022-3514.81.6.1028

Hofstede, G. (1980). Culture's consequences: International differences in work-related values. Beverly Hills, CA: Sage Publications.

Hong, Y.-Y., Morris, M. W., Chiu, C.-Y., \& Benet-Martínez, V. (2000). Multicultural minds: 
A dynamic constructivist approach to culture and cognition. American Psychologist, 55(7), 709-720. https://doi.org/10.1037//0003-066x.55.7.709

Hunzaker, M. B. F. (2016). Cultural Sentiments and Schema-Consistency Bias in Information Transmission. American Sociological Review, 81(6), 1223-1250.

https://doi.org/10.1177/0003122416671742

Imada, T., \& Yussen, S. R. (2012). Reproduction of cultural values: A cross-cultural examination of stories people create and transmit. Personality and Social Psychology Bulletin, 38(1), 114-128. https://doi.org/10.1177/0146167211421938

Inglehart, R., \& Baker, W. E. (2000). Modernization, cultural change, and the persistence of traditional values. American Sociological Review, 19-51.

Inglehart, R. F. (2016). How much should we worry? Journal of Democracy, 27(3), 18-23. https://doi.org/10.1353/jod.2016.0053

Kashima, Y. (2014). How can you capture cultural dynamics? Frontiers in Psychology. https://doi.org/10.3389/fpsyg.2014.00995

Kashima, Y. (2016a). Culture and psychology in the 21st century: Conceptions of culture and person revised. Journal of Cross-Cultural Psychology, 47(1), 4-20.

Kashima, Y. (2016b). Cultural dynamics. Current Opinion in Psychology, 8, 93-97.

Kashima, Y. (2018). What is culture for? In D. Matsumoto (Ed.), Handbook of culture and psychology (2nd ed.). New York, NY: Oxford University Press.

Kashima, Y., \& Kashima, E. S. (2003). Individualism, GNP, Climate, And Pronoun Drop: Is Individualism Determined by Affluence and Climate, or Does Language Use Play a Role? Journal of Cross-Cultural Psychology, 34(1), 125-134. https://doi.org/10.1177/0022022102239159

Kashima, Y., Kirley, M., Stivala, A., \& Robins, G. (2017). Modeling cultural dynamics. In R. R. Valacher, S. J. Read, \& A. Nowak (Eds.), Computational social psychology (pp. 281- 
307). New York: Taylor \& Francis.

Kashima, Y., Klein, O., \& Clark, A. E. (2007). Grounding: Sharing information in social interaction. In K. Fiedler (Ed.), Social communication (pp. 27-77). New York, NY: Psychology Press.

Kashima, Y., Laham, S. M., Dix, J., Levis, B., Wong, D., \& Wheeler, M. (2015). Social transmission of cultural practices and implicit attitudes. Organizational Behavior and Human Decision Processes, 127, 113-125. https://doi.org/10.1016/j.obhdp.2014.05.005

Kashima, Y., Lyons, A., \& Clark, A. E. (2013). The maintenance of cultural stereotypes in the conversational retelling of narratives. . Asian Journal of Social Psychology, 16, 6070.

Kashima, Y., Peters, K., \& Whelan, J. (2008). Culture, narrative, and human agency. In R. M. Sorrentino \& S. Yamaguchi (Eds.), Handbook of motivation and cognition across cultures (pp. 393-421). San Diego, CA: Academic Press.

Kashima, Y., Wilson, S., Lusher, D., Pearson, L. J., \& Pearson, C. (2013). The acquisition of perceived descriptive norms as social category learning in social networks. Social Networks, 35, 711-719. https://doi.org/10.1016/j.socnet.2013.06.002

Kemp, C., \& Regier, T. (2012). Kinship categories across languages reflect general communicative principles. Science, 336(6084), 1049-1054.

https://doi.org/10.1126/science.1218811

Kemp, C., Xu, Y., \& Regier, T. (2018). Semantic Typology and Efficient Communication. Annual Review of Linguistics, 4(1), 109-128. https://doi.org/10.1146/annurevlinguistics-011817-045406

Kirby, S. (2001). Spontaneous evolution of linguistic structure - An iterated learning model of the emergence of regularity and irregularity. IEEE Transactions on Evolutionary Computation, 5(2), 102-110. https://doi.org/10.1109/4235.918430 
Kirby, S., Tamariz, M., Cornish, H., \& Smith, K. (2015). Compression and communication in the cultural evolution of linguistic structure. Cognition, 141, 87-102. https://doi.org/10.1016/j.cognition.2015.03.016

Klemm, K., Eguíluz, V. M., Toral, R., \& San Miguel, M. (2003a). Global Culture: A NoiseInduced Transition in Finite Systems. Physical Review E, 67(4), 045101(R).

Klemm, K., Eguíluz, V. M., Toral, R., \& San Miguel, M. (2003b). Nonequilibrium transitions in complex networks: A model of social interaction. Physical Review E, 67(2). https://doi.org/10.1103/PhysRevE.67.026120

Knöbl, W. (2003). Theories that won't pass away: The never-ending story of modernization theory. In G. Delanty \& E. E. Isin (Eds.), Handbook of historical sociology (pp. 96107). London, UK: Sage.

Koplenig, A., \& Müller-Spitzer, C. (2016). Population size predicts lexical diversity, but so does the mean sea level-why it is important to correctly account for the structure of temporal data. PLoS One, 11(3), e0150771.

Koudenburg, N., Postmes, T., \& Gordijn, E. H. (2017). Beyond Content of Conversation: The Role of Conversational Form in the Emergence and Regulation of Social Structure. Personality and Social Psychology Review, 21(1), 50-71.

Kusumi, T., Hirayama, R., \& Kashima, Y. (2017). Risk Perception and Risk Talk: The Case of the Fukushima Daiichi Nuclear Radiation Risk. Risk Analysis, 37(12), 2305-2320.

Laland, K. N., Odling-Smee, J. F., \& Feldman, M. W. (2000). Niche construction, biological evolution, and cultural change. Behavioral and Brain Sciences, 23(1), 131-146. https://doi.org/10.1017/S0140525X00002417

Latané, B. (1996). Dynamic social impact: The creation of culture by communication. Journal of Communication, 46(4), 13-25.

Latané, B., \& L’Herrou, T. (1996). Spatial clustering in the conformity game: Dynamic social 
impact in electronic groups. Journal of Personality and Social Psychology, 70(6), 12181230.

Lee, T. L., Gelfand, M. J., \& Kashima, Y. (2014). The serial reproduction of conflict: Third parties escalate conflict through communication biases. Journal of Experimental Social Psychology, 54(1), 68-72. https://doi.org/10.1016/j.jesp.2014.04.006

Legare, C. H. (2017). Cumulative cultural learning: Development and diversity. Proceedings of the National Academy of Sciences of the United States of America, 114(30), 78777883. https://doi.org/10.1073/pnas.1620743114

Lewandowsky, S., Ecker, U. K. H., \& Cook, J. (2017). Beyond Misinformation: Understanding and Coping with the "Post-Truth" Era. Journal of Applied Research in Memory and Cognition, 6(4), 353-369.

Liu, D., \& Xin, Z. (2015). Birth Cohort and Age Changes in the Self-Esteem of Chinese Adolescents: A Cross-Temporal Meta-Analysis, 1996-2009. Journal of Research on Adolescence, 25(2), 366-376.

Lyons, A., \& Kashima, Y. (2003). How Are Stereotypes Maintained Through Communication? The Influence of Stereotype Sharedness. Journal of Personality and Social Psychology, 85(6), 989-1005. https://doi.org/10.1037/0022-3514.85.6.989

Markus, H. R., \& Kitayama, S. (1991). Culture and the self: Implications for cognition, emotion, and motivation. Psychological REview, 98(2), 224-253. https://doi.org/10.1037/0033-295x.98.2.224

Maurits, L., Perfors, A., \& Navarro, D. (2010). Why are some word orders more common than others? A uniform information density account. Advances in Neural Information Processing Systems, 23, 1585-1593.

Maynard, A. E., Greenfield, P. M., \& Childs, C. P. (2015). Developmental effects of economic and educational change: Cognitive representation in three generations across 
43 years in a Maya community. International Journal of Psychology, 50(1), 12-19. https://doi.org/10.1002/ijop.12129

Maynard Smith, J. (1982). Evolution and the theory of games. Cambridge, UK: Cambridge University Press.

Mesoudi, A. (2011). Cultural evolution: How Darwinian theory can explain human culture and synthesize the social sciences. University of Chicago Press.

Michel, J.-B., Shen, Y. K., Aiden, A. P., Veres, A., Gray, M. K., Pickett, J. P., ... Orwant, J. (2011). Quantitative analysis of culture using millions of digitized books. Science, $331(6014), 176-182$.

Miton, H., Claidière, N., \& Mercier, H. (2015). Universal cognitive mechanisms explain the cultural success of bloodletting. Evolution and Human Behavior, 36(4), 303-312.

Morling, B., \& Lamoreaux, M. (2008). Measuring culture outside the head: A meta-analysis of individualism-collectivism in cultural products. Personality and Social Psychology Review, 12(3), 199-221. https://doi.org/10.1177/1088868308318260

Morris, M. W., Chiu, C.-y., \& Liu, Z. (2015). Polycultural psychology. Annural Review of Psychology, 66, 631-659.

Muthukrishna, M., \& Henrich, J. (2016). Innovation in the collective brain. Phil. Trans. $R$. Soc. B, 371(1690), 20150192.

Muthukrishna, M., Shulman, B. W., Vasilescu, V., \& Henrich, J. (2014). Sociality influences cultural complexity. Proceedings of the Royal Society of London, Series B, 281(1774), 20132511. https://doi.org/10.1098/rspb.2013.2511

Nairne, J. S., \& Pandeirada, J. N. S. (2008). Adaptive memory: Remembering with a stoneage brain. Current Directions in Psychological Science, 17(4), 239-243. https://doi.org/10.1111/j.1467-8721.2008.00582.x

Nairne, J. S., Pandeirada, J. N. S., Gregory, K. J., \& VanArsdall, J. E. (2009). Adaptive 
memory: Fitness relevance and the hunter-gatherer mind. Psychological Science, 20(6), 740-746. https://doi.org/10.1111/j.1467-9280.2009.02356.x

Nairne, J. S., VanArsdall, J. E., Pandeirada, J. N. S., Cogdill, M., \& LeBreton, J. M. (2013). Adaptive memory: The mnemonic value of animacy. Psychological Science, 24(10), 2099-2105. https://doi.org/10.1177/0956797613480803

Navarro, D., Perfors, A., Kary, A., Brown, S., \& Donkin, C. (2017). When extremists win: On the behavior of iterated learning chains when priors are heterogeneous. In G. Gunzelman, A. Howes, T. Tenbrink, \& E. Davelaar (Eds.), Proceedings of the 39th Annual Conference of the Cognitive Science Society (pp. 847-852).

Nowak, A., Gelfand, M. J., Borkowski, W., Cohen, D., \& Hernandez, I. (2016). The Evolutionary Basis of Honor Cultures. Psychological Science, 27(1), 12-24. https://doi.org/10.1177/0956797615602860

Nowak, A., Szamrej, J., \& Latané, B. (1990). From private attitudes to public opinions: A dynamic theory of social impact. Psychological Review, 97(3), 362-376.

Nowak, M. A. (2006). Five rules for the evolution of cooperation. Science, 314, 1560-1563.

Nowak, M. A., \& Sigmund, K. (1998). Evolution of indirect reciprocity by image scoring. Nature, 393(6685), 573-577. https://doi.org/10.1038/31225

Ogihara, Y. (2016). The change in self-esteem among middle school students in Japan, 19892002. Psychology, 7(11), 1343.

Ogihara, Y., Fujita, H., Tominaga, H., Ishigaki, S., Kashimoto, T., Takahashi, A., ... Uchida, Y. (2015). Are common names becoming less common? The rise in uniqueness and individualism in Japan. Frontiers in Psychology, 6.

Ogihara, Y., Uchida, Y., \& Kusumi, T. (2016). Losing confidence over time: temporal changes in self-esteem among older children and early adolescents in Japan, 1999-2006. SAGE Open, 6(3), 2158244016666606. 
Ohtsuki, H., Hauert, C., Lieberman, E., \& Nowak, M. A. (2006). A simple rule for the evolution of cooperation on graphs and social networks. Nature, 441(7092), 502-505. https://doi.org/http://www.nature.com/nature/journal/v441/n7092/suppinfo/nature04605 _S1.html

Oishi, S. (2014). Socioecological psychology. Annual Review of Psychology, 65(1), 581-609. https://doi.org/10.1146/annurev-psych-030413-152156

Oishi, S., Graham, J., Kesebir, S., \& Galinha, I. C. (2013). Concepts of happiness across time and cultures. Personality and Social Psychology Bulletin, 39(5), 559-577. https://doi.org/10.1177/0146167213480042

Oishi, S., Kesebir, S., Eggleston, C., \& Miao, F. F. (2014). A hedonic story has a transmission advantage over a eudaimonic story. Journal of Experimental Psychology: General, 143(6), 2153-2166. https://doi.org/10.1037/a0038013

Oishi, S., \& Talhelm, T. (2012). Residential Mobility: What Psychological Research Reveals. Current Directions in Psychological Science, 21(6), 425-430. https://doi.org/10.1177/0963721412460675

Oshio, A., Okada, R., Mogaki, M., Namikawa, T., \& Wakita, T. (2014). Age and survey-year effects on self-esteem in Japan: A cross-temporal meta-analysis of scores on Rosenberg's Self-Esteem Scale. Japanese Journal of Educational Psychology, 62, 273282.

Oyserman, D. (2017). Culture three ways: Culture and subculture within countries. Annual Review of Psychology, 68, 435-463.

Perfors, A., \& Navarro, D. J. (2014). Language evolution can be shaped by the structure of the world. Cognitive Science, 38(4), 775-793. https://doi.org/10.1111/cogs.12102

Peters, K., \& Kashima, Y. (2007). From social talk to social action: Shaping the social triad with emotion sharing. Journal of Personality and Social Psychology, 93(5), 780-797. 
https://doi.org/10.1037/0022-3514.93.5.780

Peters, K., \& Kashima, Y. (2015). Bad habit or social good? How perceptions of gossiper morality are related to gossip content. European Journal of Social Psychology, 45, 784798.

Peters, K., Kashima, Y., \& Clark, A. (2009). Talking about others: Emotionality and the dissemination of social information. European Journal of Social Psychology, 39(2), 207-222. https://doi.org/10.1002/ejsp.523

Phalet, K., \& Schonpflug, U. (2001). Intergenerational Transmission of Collectivism and Achievement Values in Two Acculturation Contexts: The Case of Turkish Families in Germany and Turkish and Moroccan Families in the Netherlands. Journal of CrossCultural Psychology, 32(2), 186-201. https://doi.org/10.1177/0022022101032002006

Piantadosi, S. T., Tily, H., \& Gibson, E. (2011). Word lengths are optimized for efficient communication. Proceedings of the National Academy of Sciences, 108(9), 3526-3529. https://doi.org/10.1073/pnas.1012551108

Pyszczynski, T., Solomon, S., \& Greenberg, J. (2015). Thirty Years of Terror Management Theory: From Genesis to Revelation. In J. M. Olson \& M. P. Zanna (Eds.), Advances in Experimental Social Psychology, Vol 52 (Vol. 52, pp. 1-70).

https://doi.org/10.1016/bs.aesp.2015.03.001

Rand, D. G., \& Nowak, M. A. (2013). Human cooperation. Trends Cogn Sci, 17(8), 413-425. https://doi.org/10.1016/j.tics.2013.06.003

Ravignani, A., Delgado, T., \& Kirby, S. (2017). Musical evolution in the lab exhibits rhythmic universals. Nature Human Behaviour, 1(1). https://doi.org/10.1038/s41562016-0007

Reali, F., \& Griffiths, T. L. (2009). The evolution of frequency distributions: Relating regularization to inductive biases through iterated learning. Cognition, 111(3), 317-328. 
https://doi.org/10.1016/j.cognition.2009.02.012

Richerson, P. J., Baldini, R., Bell, A. V, Demps, K., Frost, K., Hillis, V., ... Zefferman, M. (2016). Cultural group selection plays an essential role in explaining human cooperation: A sketch of the evidence. Behavioral and Brain Sciences. https://doi.org/10.1017/S0140525X1400106X, e30

Rimé, B. (2009). Emotion elicits the social sharing of emotion: Theory and empirical review. Emotion Review, 1(1), 60-85. https://doi.org/10.1177/1754073908097189

Riolo, R. L., Cohen, M. D., \& Axelrod, R. (2001). Evolution of cooperation without reciprocity. Nature, 414(6862), 441-443. Retrieved from http://dx.doi.org/10.1038/35106555

Rothstein, B., \& Stolle, D. (2008). The state and social capital - An institutional theory of generalized trust. Comparative Politics, 40(4), 441-459.

Sabatier, C., \& Lannegrand-Willems, L. (2005). Transmission of family values and attachment: a French three-generation study. Applied Psychology, 54(3), 378-395.

Santos, H. C., Varnum, M. E. W., \& Grossmann, I. (2017). Global increases in individualism. Psychological Science, 28(9), 1228-1239.

Schaller, M., Conway III, L. G., \& Tanchuk, T. L. (2002). Selective pressures on the once and future contents of ethnic stereotypes: Effects of the communicability of traits. Journal of Personality and Social Psychology, 82(6), 861-877.

https://doi.org/10.1037//0022-3514.82.6.861

Schonpflug, U. (2001). Intergenerational Transmission of Values: The Role of Transmission Belts. Journal of Cross-Cultural Psychology, 32(2), 174-185. https://doi.org/10.1177/0022022101032002005

Segall, M. H., Campbell, D. T., \& Herskovits, M. J. (1966). The influence of culture on visual perceptions. Indianapolis, IN: Bobbs-Merrill. 
Shibanai, Y., Yasuno, S., \& Ishiguro, I. (2001). Effects of Global Information Feedback on Diversity: Extensions to Axelrod's Adaptive Culture Model. Journal of Conflict Resolution, 45(1), 80-96. https://doi.org/10.1177/0022002701045001004

Shteynberg, G., \& Galinsky, A. D. (2011). Implicit coordination: Sharing goals with similar others intensifies goal pursuit. Journal of Experimental Social Psychology, 47(6), 12911294. https://doi.org/10.1016/j.jesp.2011.04.012

Sigmund, K., De Silva, H., Traulsen, A., \& Hauert, C. (2010). Social learning promotes institutions for governing the commons. Nature, 466(7308), 861-863. https://doi.org/10.1038/nature09203

Simonton, D. K. (2011). Creativity and Discovery as Blind Variation: Campbell's (1960) BVSR Model After the Half-Century Mark. Review of General Psychology, 15(2), 158174. https://doi.org/10.1037/a0022912

Sindi, S. S., \& Dale, R. (2016). Culturomics as a data playground for tests of selection: Mathematical approaches to detecting selection in word use. Journal of Theoretical Biology, 405(Supplement C), 140-149. https://doi.org/https://doi.org/10.1016/j.jtbi.2015.12.012

Skrebyte, A., Garnett, P., \& Kendal, J. R. (2016). Temporal Relationships Between Individualism-Collectivism and the Economy in Soviet Russia. Journal of CrossCultural Psychology, 47(9), 1217-1235. https://doi.org/doi:10.1177/0022022116659540

Smith, E. R. (2014). Evil acts and malicious gossip: A multiagent model of the effects of gossip in socially distributed person perception. Personality and Social Psychology Review, 18(4), 311-325.

Smith, K., Perfors, A., Fehér, O., Samara, A., Swoboda, K., \& Wonnacott, E. (2017). Language learning, language use and the evolution of linguistic variation. Philosophical Transactions of the Royal Society B: Biological Sciences, 372(1711), 20160051. 
https://doi.org/10.1098/rstb.2016.0051

Smith, K., \& Wonnacott, E. (2010). Eliminating unpredictable variation through iterated learning. Cognition, 116(3), 444-449. https://doi.org/10.1016/j.cognition.2010.06.004

Sommerfeld, R. D., Krambeck, H. J., Semmann, D., \& Milinski, M. (2007). Gossip as an alternative for direct observation in games of indirect reciprocity. Proc Natl Acad Sci U S A, 104(44), 17435-17440. https://doi.org/10.1073/pnas.0704598104

Sperber, D. (1996). Explaining culture: A naturalistic approach. Oxford, UK: Blackwell.

Stivala, A., Kashima, Y., \& Kirley, M. (2016). Culture and cooperation in a spatial public goods game. Physical Review E, 94(3), 32303.

Stubbersfield, J. M., Tehrani, J. J., \& Flynn, E. G. (2015). Serial killers, spiders and cybersex: Social and survival information bias in the transmission of urban legends. British Journal of Psychology, 106(2), 288-307. https://doi.org/10.1111/bjop.12073

Stubbersfield, J. M., Tehrani, J. J., \& Flynn, E. G. (2017). Chicken tumours and a fishy revenge: Evidence for emotional content bias in the cumulative recall of urban legends. Journal of Cognition and Culture, 17(1-2), 12-26. https://doi.org/10.1163/1568537312342189

Suchow, J. W., Bourgin, D. D., \& Griffiths, T. L. (2017). Evolution in Mind: Evolutionary Dynamics, Cognitive Processes, and Bayesian Inference. Trends in Cognitive Sciences. https://doi.org/10.1016/j.tics.2017.04.005

Sun, J. H., \& Ryder, A. G. (2016). The Chinese Experience of Rapid Modernization: Sociocultural Changes, Psychological Consequences? Frontiers in Psychology, 7. https://doi.org/10.3389/fpsyg.2016.00477

Talhelm, T., Zhang, X., Oishi, S., Shimin, C., Duan, D., Lan, X., \& Kitayama, S. (2014). Large-scale psychological differences within China explained by rice versus wheat agriculture. Science, 344(6184), 603-608. https://doi.org/10.1126/science.1246850 
Tan, R., \& Fay, N. (2011). Cultural transmission in the laboratory: Agent interaction improves the intergenerational transfer of information. Evolution and Human Behavior, 32(6), 399-406. https://doi.org/10.1016/j.evolhumbehav.2011.01.001

Taylor, C., \& Nowak, M. A. (2007). Transforming the dilemma. Evolution, 61(10), 22812292. https://doi.org/10.1111/j.1558-5646.2007.00196.x

Thomas, K. A., DeScioli, P., Haque, O. S., \& Pinker, S. (2014). The psychology of coordination and common knowledge. Journal of Personality and Social Psychology, 107(4), 657-676. https://doi.org/10.1037/a0037037

Tönnies, F. (1963). Community and society (C. P. Loomis, Trans.). New York: Harper \& Row.

Tria, F., Loreto, V., Servedio, V. D. P., \& Strogatz, S. H. (2014). The dynamics of correlated novelties. Scientific Reports, 4. https://doi.org/10.1038/srep05890

Triandis, H. C. (1995). Individualism and collectivism. New directions in social psychology. Boulder, CO: Westview Press.

Trivers, R. L. (1971). The evolution of reciprocal altruism. The Quarterly Review of Biology, 46(1), 35-57. https://doi.org/10.1086/406755

Trzesniewski, K. H., \& Donnellan, M. B. (2010). Rethinking "Generation Me": A study of cohort effects from 1976-2006. Perspectives on Psychological Science, 5, 58-75.

Turchin, P., Currie, T. E., Turner, E. A. L., \& Gavrilets, S. (2013). War, space, and the evolution of Old World complex societies. Proceedings of the National Academy of Sciences, 110(41), 16384-16389.

Turner, J. C. (1987). Rediscovering the social group: A self-categorization theory. Oxford, UK: Basil Blackwell.

Twenge, J. M., Abebe, E. M., \& Campbell, W. K. (2010). Fitting In or Standing Out: Trends in American Parents' Choices for Children's Names, 1880-2007. Social Psychological 
and Personality Science, 1(1), 19-25. https://doi.org/10.1177/1948550609349515

Twenge, J. M., \& Campbell, W. K. (2001). Age and birth cohort differences in self-esteem: A cross-temporal meta-analysis. Personality and Social Psychology Review, 5(4), 321344. https://doi.org/10.1207/s15327957pspr0504_3

Twenge, J. M., \& Campbell, W. K. (2008). Increases in positive self-views among high school students: birth-cohort changes in anticipated performance, self-satisfaction, selfliking, and self-competence. Psychological Science, 19(11), 1082-1086. https://doi.org/10.1111/j.1467-9280.2008.02204.x

Twenge, J. M. \& Campbell, W. K. (2010). Birth cohort differences in the Monitoring the Future dataset and elsewhere: Further evidence for Generation Me - Commentary on Trzesniewsk \& Donnelan (2010). Perspectives on Psychological Science, 5, 81-88.

Twenge, J. M., Campbell, W. K., \& Carter, N. T. (2014). Declines in trust in others and confidence in institutions among American adults and late adolescents, 1972-2012. Psychological Science, 25, 1914-1923.

Twenge, J. M., Campbell, W. K., \& Gentile, B. (2012). Increases in individualistic words and phrases in American books, 1960-2008. PLoS One, 7(7), e40181. https://doi.org/10.1371/journal.pone.0040181

Twenge, J. M., Campbell, W. K., \& Gentile, B. (2013). Changes in pronoun use in American books and the rise of individualism, 1960-2008. Journal of Cross-Cultural Psychology, 44(3), 406-415. https://doi.org/10.1177/0022022112455100

Twenge, J. M., Carter, N. T., \& Campbell, W. K. (2017). Age, Time Period, and Birth Cohort Differences in Self-Esteem: Reexamining a Cohort-Sequential Longitudinal Study. Journal of Personality and Social Psychology, 112(5), E9-E17. https://doi.org/10.1037/pspp0000122

Twenge, J. M. \& Foster, J. D. (2010). Birth cohort increases in Narcissistic personality traits 
among American college students, 1982-2009. Social Psychological and Personality Science, 1(1), 99-106. DOI: 10.1177/1948550609355719

Twenge, J. M., Honeycutt, N., Prislin, R., \& Sherman, R. A. (2016). More Polarized but More Independent: Political Party Identification and Ideological Self-Categorization Among US Adults, College Students, and Late Adolescents, 1970-2015. Personality and Social Psychology Bulletin, 42(10), 1364-1383.

Twenge, J. M., Konrath, S., Foster, J. D., Campbell, W. K., \& Bushman, B. J. (2008). Egos inflating over time: a cross-temporal meta-analysis of the Narcissistic Personality Inventory. J Pers, 76(4), 828-875. https://doi.org/10.1111/j.1467-6494.2008.00507.x

Twenge, J. M., Zhang, L., \& Im, C. (2004). It's beyond my control: A cross-temporal metaanalysis of increasing externality in locus of control, 1960-2002. Personality and Social Psychology Review, 8(3), 308-319.

Uskul, A. K., Kitayama, S., \& Nisbett, R. E. (2008). Ecocultural basis of cognition: Farmers and fishermen are more holistic than herders. Proceedings of the National Academy of Sciences of the United States of America, 105(25), 8552-8556. https://doi.org/10.1073/pnas.0803874105

Valori, L., Picciolo, F., Allansdottir, A., \& Garlaschelli, D. (2012). Reconciling long-term cultural diversity and short-term collective social behavior. Proceedings of the National Academy of Sciences of the United States of America, 109(4), 1068-1073. https://doi.org/10.1073/pnas.1109514109

Van de Vliert, E. (2013). Climato-economic habitats support patterns of human needs, stresses, and freedoms. Behavioral and Brain Sciences, 36(5), 465-480. https://doi.org/10.1017/S0140525X12002828

Varnum, M. E. W., \& Grossmann, I. (2017). Cultural change: The how and the why. Perspectives on Psychological Science. 
Vignoles, V. L., Owe, E., Becker, M., Smith, P. B., Easterbrook, M. J., Brown, R., ... Cadena, M. P. (2016). Beyond the "east-west"dichotomy: Global variation in cultural models of selfhood. Journal of Experimental Psychology: General, 145(8), 966-1000.

Weisbuch, M., \& Ambady, N. (2009). Unspoken cultural influence: Exposure to and influence of nonverbal bias. Journal of Personality and Social Psychology, 96(6), 11041119. https://doi.org/10.1037/a0015642

Weisbuch, M., Pauker, K., \& Ambady, N. (2009). The subtle transmission of race bias via televised nonverbal behavior. Science, 326(5960), 1711-1714. https://doi.org/10.1126/science.1178358

West, S. A., Griffin, A. S., \& Gardner, A. (2007). Evolutionary explanations for cooperation. Curr Biol, 17(16), R661-72. https://doi.org/10.1016/j.cub.2007.06.004

Whiten, A., Caldwell, C. A., \& Mesoudi, A. (2016). Cultural diffusion in humans and other animals. Current Opinion in Psychology, 8, 15-21.

Wilson, D. S., Hayes, S. C., Biglan, A., \& Embry, D. D. (2014). Evolving the future: toward a science of intentional change. Behav Brain Sci, 37(4), 395-416. https://doi.org/10.1017/S0140525X13001593

Xin, Z., Niu, J., \& Chi, L. (2012). Birth cohort changes in Chinese adolescents' mental health. International Journal of Psychology, 47(4), 287-295.

Xin, Z., \& Xin, S. (2017). Marketization process predicts trust decline in China. Journal of Economic Psychology, 62(Supplement C), 120-129. https://doi.org/https://doi.org/10.1016/j.joep.2017.07.001

Xu, Y., \& Hamamura, T. (2014). Folk beliefs of cultural changes in China. Frontiers in Psychology, 5.

Yamagishi, T. (2017). Individualism-collectivism, the rule of law, and general trust. In P. A. M. Van Lange, B. Rockenbach, \& T. Yamagishi (Eds.), Trust in social dilemmas (pp. 
197-214). Oxford, UK: Oxford University Press.

Youn, H. J., Strumsky, D., Bettencourt, L. M. A., \& Lobo, J. (2015). Invention as a combinatorial process: evidence from US patents. Journal of the Royal Society Interface, 12(106). https://doi.org/10.1098/rsif.2015.0272

Younes, N., \& Reips, U.-D. (2017). The changing psychology of culture in German-speaking countries: A Google Ngram study. International Journal of Psychology, n/a-n/a. https://doi.org/10.1002/ijop.12428

Zeng, R., \& Greenfield, P. M. (2015). Cultural evolution over the last 40 years in China: Using the Google Ngram Viewer to study implications of social and political change for cultural values. International Journal of Psychology, 50(1), 47-55.

Zhang, R., \& Weng, L. (2017). Not all cultural values are created equal: Cultural change in China reexamined through Google books. International Journal of Psychology. 


\section{University Library}

\section{- M M N E R VA A gateway to Melbourne's research publications}

Minerva Access is the Institutional Repository of The University of Melbourne

Author/s:

Kashima, Y;Bain, PG;Perfors, A

Title:

The Psychology of Cultural Dynamics: What Is It, What Do We Know, and What Is Yet to Be Known?

Date:

2019-01-01

Citation:

Kashima, Y., Bain, P. G. \& Perfors, A. (2019). The Psychology of Cultural Dynamics: What Is It, What Do We Know, and What Is Yet to Be Known?. Fiske, ST (Ed.). ANNUAL REVIEW OF PSYCHOLOGY, VOL 70, (First), 70, pp.499-529. ANNUAL REVIEWS.

Persistent Link:

http://hdl.handle.net/11343/252749 